Article

\title{
Dereplication Strategies for Targeted Isolation of New Antitrypanosomal Actinosporins A and B from a Marine Sponge Associated-Actinokineospora sp. EG49
}

\section{Usama Ramadan Abdelmohsen ${ }^{1, \dagger ;}$, Cheng Cheng ${ }^{1,2,}$, Christina Viegelmann ${ }^{2}$, Tong Zhang ${ }^{2}$, Tanja Grkovic ${ }^{3}$, Safwat Ahmed ${ }^{4}$, Ronald J. Quinn ${ }^{3}$, Ute Hentschel ${ }^{1} *$ and RuAngelie Edrada-Ebel ${ }^{2, *}$}

1 Department of Botany II, Julius-von-Sachs Institute for Biological Sciences, University of Würzburg, Julius-von-Sachs-Platz 3, Würzburg D-97082, Germany; E-Mails: usama.ramadan@ @uni-wuerzburg.de (U.R.A.); cheng.cheng1@uni-wuerzburg.de (C.C.)

2 Strathclyde Institute of Pharmacy and Biomedical Sciences, University of Strathclyde, The John Arbuthnott Building, 161 Cathedral Street, Glasgow G4 0NR, UK;

E-Mails: c.cheng@strath.ac.uk (C.C.); christina.viegelmann@strath.ac.uk (C.V.); tong.zhang.101@strath.ac.uk (T.Z.)

3 Eskitis Institute, Griffith University, Brisbane, QLD 4111, Australia; E-Mails: t.grkovic@griffith.edu.au (T.G.); r.quinn@griffith.edu.au (R.J.Q.)

4 Department of Pharmacognosy, Faculty of Pharmacy, Suez Canal University, Ismailia 41522, Egypt; E-Mail: safwat_aa@yahoo.com

$\dagger$ Permanent address: Department of Pharmacognosy, Faculty of Pharmacy, Minia University, Minia 61519, Egypt

* These two authors contributed equally to this work.

* Authors to whom correspondence should be addressed;

E-Mails: ute.hentschel@uni-wuerzburg.de (U.H.); ruangelie.edrada-ebel@ strath.ac.uk (R.E.-E.); Tel.: +49-931-31-82581 (U.H.); Fax: +49-931-31-86235 (U.H.); Tel.:+44-141-548-5968 (R.E.-E.); Fax: +44-141-552-2562 (R.E.-E.).

Received: 11 October 2013; in revised form: 22 January 2014 / Accepted: 8 February 2014 / Published: 6 March 2014

\footnotetext{
Abstract: High resolution Fourier transform mass spectrometry (HRFTMS) and nuclear magnetic resonance (NMR) spectroscopy were employed as complementary metabolomic tools to dereplicate the chemical profile of the new and antitrypanosomally active sponge-associated bacterium Actinokineospora sp. EG49 extract. Principal Component
} 
(PCA), hierarchical clustering (HCA), and orthogonal partial least square-discriminant analysis (OPLS-DA) were used to evaluate the HRFTMS and NMR data of crude extracts from four different fermentation approaches. Statistical analysis identified the best culture one-strain-many-compounds (OSMAC) condition and extraction procedure, which was used for the isolation of novel bioactive metabolites. As a result, two new $O$-glycosylated angucyclines, named actinosporins A (1) and B (2), were isolated from the broth culture of Actinokineospora sp. strain EG49, which was cultivated from the Red Sea sponge Spheciospongia vagabunda. The structures of actinosporins A and B were determined by 1D- and 2D-NMR techniques, as well as high resolution tandem mass spectrometry. Testing for antiparasitic properties showed that actinosporin A exhibited activity against Trypanosoma brucei brucei with an $I C_{50}$ value of $15 \mu \mathrm{M}$; however no activity was detected against Leishmania major and Plasmodium falciparum, therefore suggesting its selectivity against the parasite Trypanosoma brucei brucei; the causative agent of sleeping sickness.

Keywords: actinosporins; Spheciospongia vagabunda; Actinokineospora; anti-trypanosomal; dereplication; secondary metabolomics

\section{Introduction}

Dereplication refers to the rapid identification of known secondary metabolites and their quantification in crude unfractionated extracts [1-3]. This can be a demanding undertaking, because secondary metabolites occur in a wide range of concentrations along with enormous variations in their chemical and physical properties. Therefore, reliable, robust, and selective analytical methods are required to identify secondary metabolites in complex mixtures. To date, LC-UV/MS signatures have been successfully used with AntiBase and MarinLit databases [4]. Owing to the superior sensitivity of mass spectrometry and reproducibility of NMR spectroscopy, they are suitable complementary analytical tools for natural products identification. The large data set produced by NMR and MS experiments requires multivariate analysis for data interpretation, such as principal component analysis (PCA), hierarchical clustering analysis (HCA), and orthogonal partial least square-discriminant analysis (OPLS-DA) [5]. Application of these analytical and statistical methods in metabolomics, facilitates the discovery of potentially novel microbial secondary metabolites as well as the bioassay-guided isolation work [1,2,6-12]. As an example, Hou and co-workers [13] employed untargeted secondary metabolomics using LC/MS-PCA as an effective strategy for strain prioritization to yield the most chemically diverse and novel natural products for drug discovery. Metabolomics is not yet widely applied as a natural product screening tool, although it has several advantages over the classical bioassay-guided isolation approach. By using combinations of different analytical methods, the bioassay-guided isolation route is shortened and putative identification of potentially new natural products is rapidly achieved $[3,14]$.

Actinomycetes are frequently isolated from different marine, filter-feeding invertebrates, including sponges, corals, tunicates, and jellyfish [15-19]. Marine actinomycetes are still an underexplored source of secondary metabolites and lead molecules with biotechnological, therapeutic, and industrial 
applications [20,21]. Metabolites from these microorganisms were shown to exhibit diverse activities, such as antibacterial, antifungal, antiparasitic, immunomodulatory, anti-inflammatory, anti-protease, antioxidant, and anticancer activities [22-25]. These activities are mediated by several classes of natural products, including polyketides, alkaloids, peptides, and terpenes [26-29]. Members of the genus Actinokineospora have been cultivated from terrestrial soils and plants [30,31], and were recently isolated for the first time from a marine sponge [32]. This rare genus is not yet known for the production of secondary metabolites.

Angucyclines are a large family of actinomycete-derived polyketide antibiotics with a four-ring skeleton that constitutes the aglycone part [33,34]. Structurally, angucyclines consist of a benzanthraquinone core, which is usually $C$ - or $O$-glycosylated with sugar chains of various lengths, including the three main sugar moieties: olivose, rhodinose, and amicetose, such as rabelomycin and landomycins families (e.g., landomycin P) [35,36]. Angucyclines showed diverse activities, including antitumor, antibacterial, inhibition of platelet aggregation, and enzyme inhibitory activities [37,38]. They were isolated from bacterial genera, such as Amycolatopsis and Nocardia, and frequently from the genus Streptomyces [39-41], such as most recently from the deep sea sediment-derived Streptomyces lusitanus SCSIO LR32 [42].

Figure 1. Work flowchart.

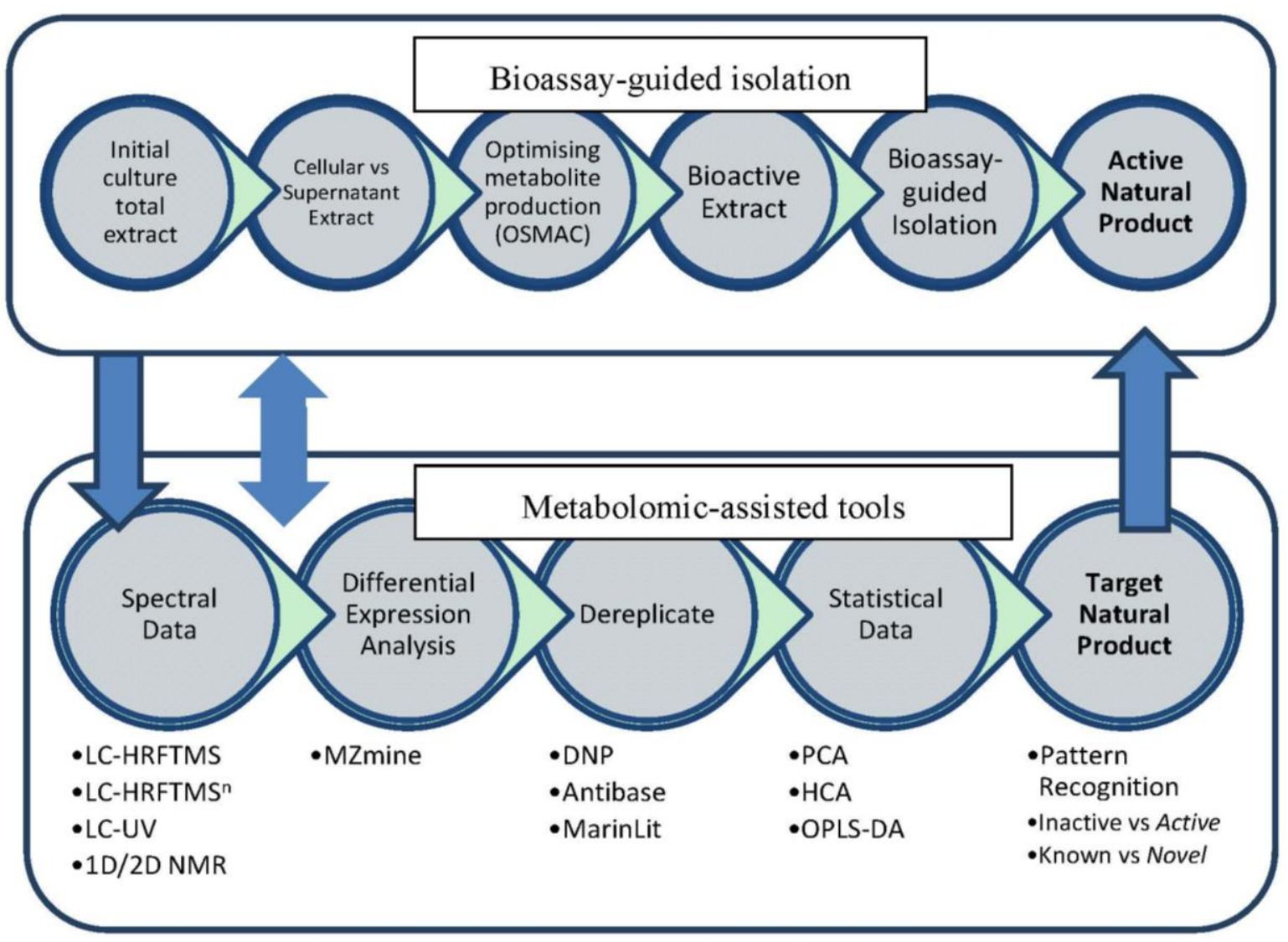

The goal of this work was to implement untargeted secondary metabolomics in the dereplication of crude extracts of Actinokineospora sp. EG49 [32] that displayed antitrypanosomal activity. Our approach was two-pronged (Figure 1). First, we aimed to optimize the production of the antitrypanosomal metabolites by the "one-strain-many-compounds" (OSMAC) approach [43]. The dereplication strategy 
employed both MS and NMR to cross validate and quantify the bioactive metabolites in four different fermentation approaches: ISP2 agar, ISP2 liquid broth, ISP2 liquid broth with XAD-16, and ISP2 liquid broth with calcium alginate beads, as well as between two different extraction procedures. Secondly, we aimed to identify putative novel bioactive compounds from the strain EG49.

\section{Results and Discussion}

\subsection{Metabolomic Profiling of the Crude Ethyl Acetate Extract of ISP2 Agar Culture of EG49}

The crude ethyl acetate extract of ISP2 agar culture of Actinokineospora sp. EG49 isolate exhibited $100 \%$ growth inhibition of Trypanosoma brucei brucei S427 at a concentration of $20 \mu \mathrm{g} / \mathrm{mL}$. This prompted us to perform further chemical work on this bioactive isolate. We used two independent approaches: metabolomics-guided optimisation of the production of the biologically active component and, in parallel, bioassay-guided isolation of the active principle. Dereplication of the secondary metabolites from the antitrypanosomally active isolate Actinokineospora sp. strain EG49 was achieved by high resolution Fourier transform mass spectrometry (HRFTMS) using the Exactive-Orbitrap and high resolution NMR. Secondary metabolites were tentatively identified with the aid of existing high resolution MS and NMR records from online and in-house databases, i.e., MarinLit, a database for marine natural products and AntiBase, a database of microbial secondary metabolites. The software tools MZmine 2.10 [44,45] and SIMCA 13.0.2 were utilized to perform differential analysis of sample populations to find significantly expressed features relating to complex biomarkers between parameter variables. Only Antibase and Marinlit databases were employed in this study for a more practical discriminatory search of taxonomically-related microbial metabolites. The limitation of a dereplication study for secondary metabolites, particularly from marine sources, is the difficulty to attain a reference standard for every found "hit" from the database. To ensure the correctness of the identification of the basic structure of the identified peaks, UV, MS/MS data, and NMR spectral data were used to support the results. These combinatory methods of identification were more reliable than utilizing MS/MS data alone for which no global library is available to this date. MS/MS data are highly dependent on various parameters, such as source settings and potential differences between the skimmers as well as between instruments.

Prior to dereplication, molecular formula prediction was done utilizing MZmine's algorithm, which employs a combination of empirical techniques that included isotope pattern matching [44]. Using the positive and negative mode electrospray ionization spectral data at a MW tolerance within 5 ppm, known compounds were tentatively identified with AntiBase and MarinLit. Most of the identified compounds were previously isolated from the genus Streptomyces (Supplementary Information, Table S1). The identified compounds are highlighted in the total ion chromatogram showing the distribution of the known and unknown compounds (Figure 2). The known compounds detected from the dereplication study are shown in Figure 3. The anthraquinone structure was identified from their typical UV spectrum as well as through the ${ }^{13} \mathrm{C}$ NMR spectral data of the crude extract where signals were observed between 160 and 200 ppm (see Supplementary Information, Figure S1). As previously observed by Nielsen's group [12], the negative mode revealed the presence of a variety of quinone compounds (9-18, 20-24) (Figure 3). From the unidentified peak list, as shown in Supplementary 
Information, Table S2, new quinone congeners were detected and the molecular formula prediction, the double bond equivalence, and $\mathrm{MS}^{\mathrm{n}}$ data are summarized in the table. The $\mathrm{MS}^{2}$ and/or $\mathrm{MS}^{3}$ data revealed a glycosidic fragment of $146 \mathrm{Da}$, while $\mathrm{MS}^{3}$ fragment gave a Ring Double Bond (RDB) of 14 for the anthraquinone core (see Supplementary Information, Figure S2 for the mass spectral data and Table 1 for a brief illustration of the MS/MS fragmentation for the most intense chromatography peaks). The MS fragmentation experiments confirmed the presence of gylcosidic angucyclines and new compounds against those found in the database. One example is elloramycin E, which is also an anthraquinone congener with just one sugar unit. However, the loss of two $146 \mathrm{Da}\left[\mathrm{C}_{6} \mathrm{H}_{10} \mathrm{O}_{4}\right]$ units does suggest that the structure is a glycosidic angucycline congener.

Figure 2. Total ion chromatogram of crude ethyl acetate extract of Actinokineospora sp. EG49 ISP2 agar culture in both positive (blue line) and negative (red line) modes. The chromatogram was an output generated from MZmine; a high-throughput differential expression analysis software, which provides algorithms for peak alignment, normalization, and deconvolution. The resulting data sets were then subjected to automated dereplication.

Base peak plot, MS1, m/z 150-1000

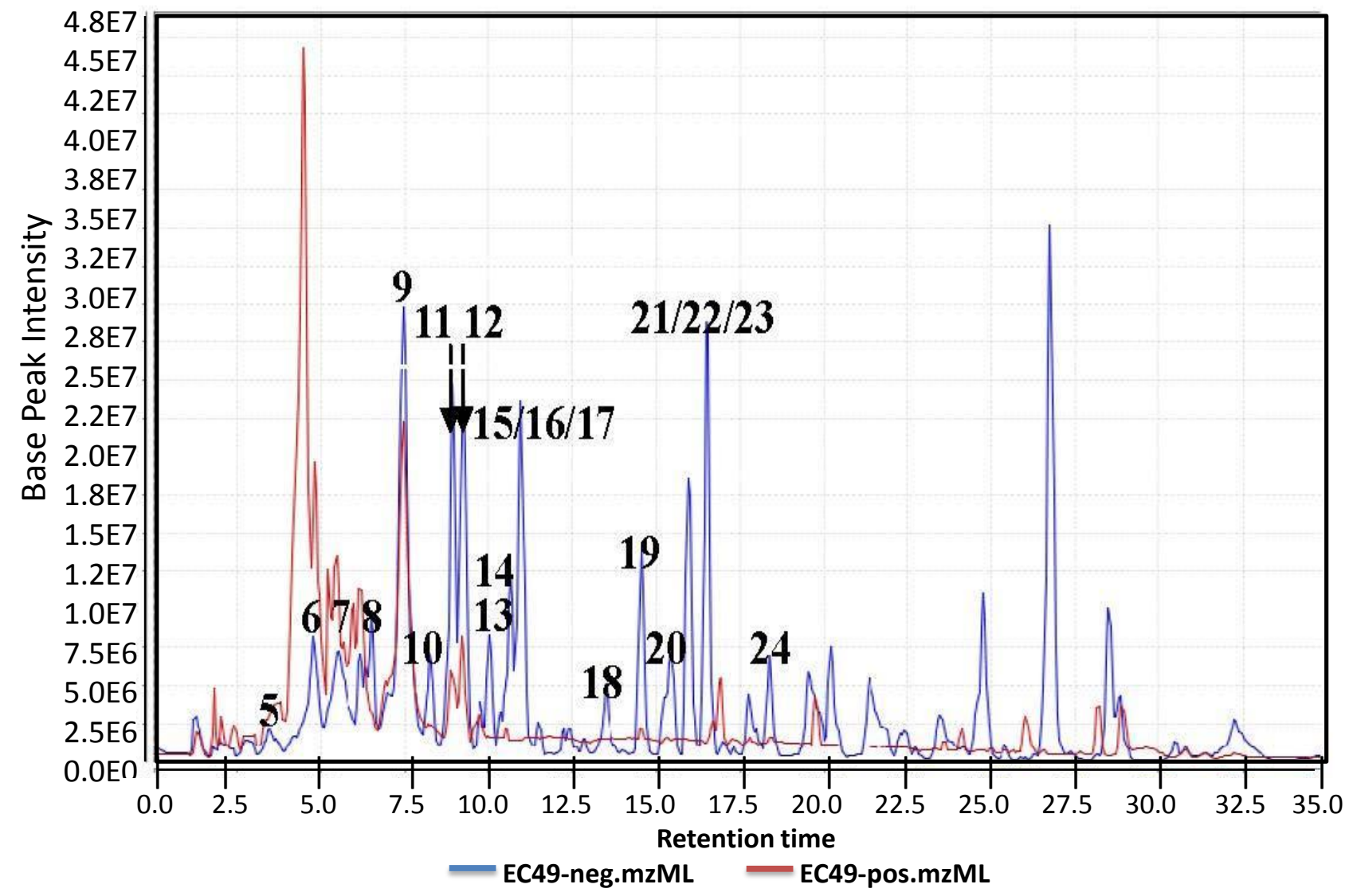


Figure 3. Compounds identified and dereplicated from high resolution mass spectral data sets of the crude ethyl acetate extract of Actinokineospora sp. EG49 ISP2 agar culture of by utilizing macros and algorithms that coupled MZmine with both in-house and commercial databases. (Some stereocenters were not assigned due to the presence of other stereoisomers found in the database. As shown in Figure 2, peaks 7 and 8 at different retention times gave the same "hit" compound, which were then numbered accordingly, indicating the possibility of chemical isomers for either peaks. Stereocenters were drawn as found in the database.)
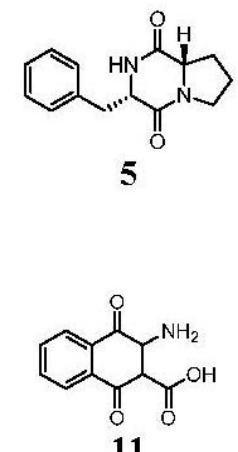

11

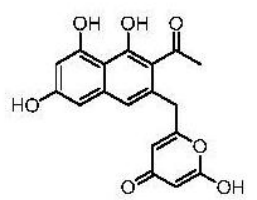

16

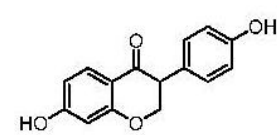

21

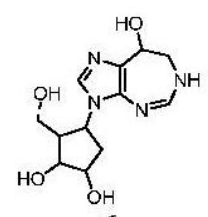

6

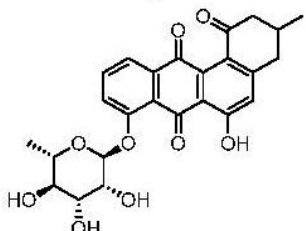

12

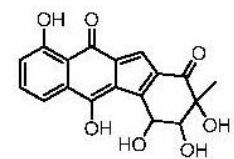

17

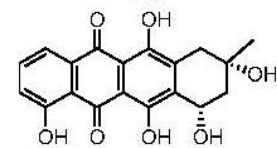

22

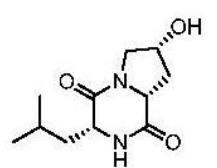

7,8

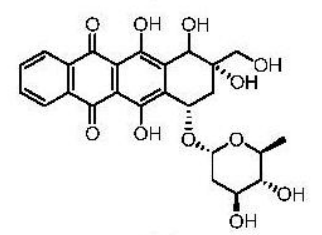

13

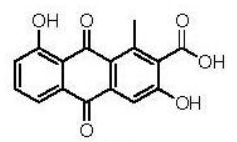

18

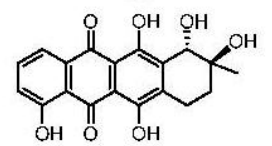

23

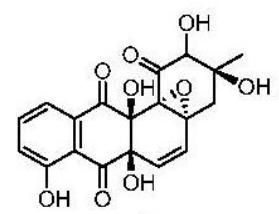

9

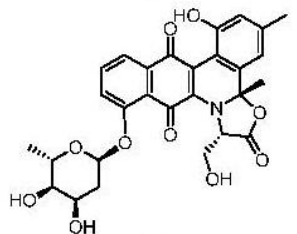

14

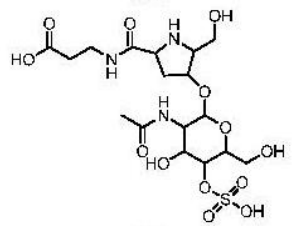

19

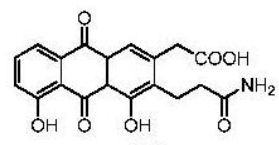

24

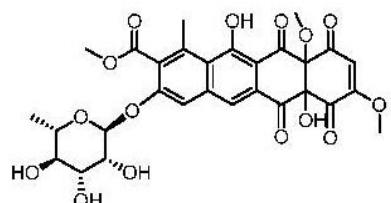

10

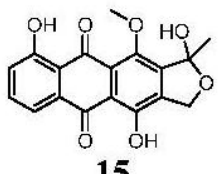

15

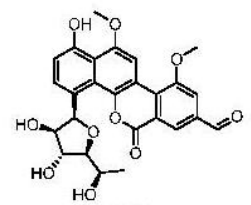

20

The presence of anthraquinones was confirmed by UV and NMR spectral data. From the photodiode array (PDA) detector, UV-Vis spectra of individual peaks identified as quinones displayed four transitions above $240 \mathrm{~nm}$ with three more intense bands near 250, 270, and $320 \mathrm{~nm}$ for a benzenoid and quinonoid moiety, respectively. On the other hand, NMR showed the presence of resonances between 12 and $13 \mathrm{ppm}$, representing the hydrogen-bound phenolic hydroxyl on the carbonyl group. Quinone analogues have been reported to have antitrypanosomal activity; the inhibitory mechanism of which is assumed to be the induction of oxidative stress against trypanothione reductase, a key enzyme involved in the trypanosomal antioxidant thiol metabolism [46]. Therefore, quinone compounds may contribute to the antitrypanosomal activity of EG49 ISP2 agar extract.

It is clear from the chromatogram that more than half of the peaks were not identified by comparison with the databases, including some of the major components that showed strong peak intensities and good resolution. The $\mathrm{m} / \mathrm{z}$ value and the predicted formula of these unidentified compounds are presented in Supplementary Information, Table S2. The high number of unidentified compounds highlights the chemical potential of this strain as a source of new metabolites. 
Table 1. MS/MS fragmentation of major peaks found in the total ion chromatogram of the crude ethyl acetate extract of Actinokineospora sp. EG49 ISP2 agar culture in the negative ionization mode.

\begin{tabular}{|c|c|c|c|c|c|}
\hline RT min & {$[\mathbf{M}-\mathbf{H}]^{-}$} & Predicted MF $[\mathrm{M}-\mathrm{H}]^{-}$ & 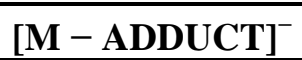 & $\mathbf{M S}^{2}$ & $\mathbf{M S}^{3}$ \\
\hline 8.10 & $\begin{array}{l}513.1398 \\
14 \mathrm{RDBE}\end{array}$ & Atramycin A (12) & $\begin{array}{c}467.13 \\
{[\mathrm{M}-\mathrm{HCOOH}]} \\
\mathrm{C}_{25} \mathrm{H}_{23} \mathrm{O}_{9}\end{array}$ & $\begin{array}{c}321.08 \\
{\left[-\mathrm{C}_{6} \mathrm{H}_{10} \mathrm{O}_{4}\right]} \\
\mathrm{C}_{19} \mathrm{H}_{13} \mathrm{O}_{5} \\
13 \mathrm{RDBE} \\
\end{array}$ & \\
\hline 8.97 & $\begin{array}{l}657.1822 \\
16 \mathrm{RDBE}\end{array}$ & Actinosporin $\mathrm{A}(\mathbf{1})$ & $\begin{array}{c}611.18 \\
{[\mathrm{M}-\mathrm{HCOOH}]} \\
\mathrm{C}_{31} \mathrm{H}_{31} \mathrm{O}_{13}\end{array}$ & 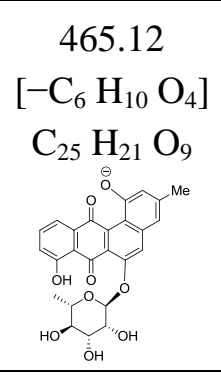 & $\begin{array}{c}319.06 \\
{\left[-\mathrm{C}_{6} \mathrm{H}_{10} \mathrm{O}_{4}\right]} \\
\mathrm{C}_{19} \mathrm{H}_{11} \mathrm{O}_{5} \\
14 \mathrm{RDBE}\end{array}$ \\
\hline 9.85 & $\begin{array}{l}641.1875 \\
16 \mathrm{RDBE}\end{array}$ & $\begin{array}{c}\mathrm{C}_{32} \mathrm{H}_{33} \mathrm{O}_{14} \\
\text { Unknown }\end{array}$ & $\begin{array}{c}595 \\
{[\mathrm{M}-\mathrm{HCOOH}]} \\
\mathrm{C}_{31} \mathrm{H}_{31} \mathrm{O}_{12}\end{array}$ & $\begin{array}{c}451.14 \\
{\left[-\mathrm{C}_{6} \mathrm{H}_{10} \mathrm{O}_{4}\right]} \\
\mathrm{C}_{25} \mathrm{H}_{23} \mathrm{O}_{8} \\
14 \mathrm{RDBE}\end{array}$ & $\begin{array}{c}305.08 \\
{\left[-\mathrm{C}_{6} \mathrm{H}_{10} \mathrm{O}_{4}\right]} \\
\mathrm{C}_{19} \mathrm{H}_{13} \mathrm{O}_{4} \\
13 \mathrm{RDBE}\end{array}$ \\
\hline 10.60 & $\begin{array}{l}657.1826 \\
16 \mathrm{RDBE}\end{array}$ & $\begin{array}{c}\mathrm{C}_{32} \mathrm{H}_{33} \mathrm{O}_{15} \\
\text { Elloramycin E* } \\
\text { * Elloramycin E not } \\
\text { two sugar units. }\end{array}$ & $\begin{array}{c}611.18 \\
\mathrm{C}_{31} \mathrm{H}_{31} \mathrm{O}_{13} \\
\text { Unknown }\end{array}$ & $\begin{array}{c}465.12 \\
{\left[-\mathrm{C}_{6} \mathrm{H}_{10} \mathrm{O}_{4}\right]} \\
\mathrm{C}_{25} \mathrm{H}_{21} \mathrm{O}_{9} \\
15 \mathrm{RDBE}\end{array}$ & $\begin{array}{c}319.06 \\
{\left[-\mathrm{C}_{6} \mathrm{H}_{10} \mathrm{O}_{4}\right]} \\
\mathrm{C}_{19} \mathrm{H}_{11} \mathrm{O}_{5} \\
14 \mathrm{RDBE}\end{array}$ \\
\hline 15.37 & $\begin{array}{l}467.1353 \\
14 \mathrm{RDBE}\end{array}$ & $\begin{array}{l}\text { ÖH } \\
\text { BE-12406-A }\end{array}$ & & $\begin{array}{c}320.07 \\
{\left[-\mathrm{C}_{6} \mathrm{H}_{10} \mathrm{O}_{4}\right]} \\
\mathrm{C}_{19} \mathrm{H}_{12} \mathrm{O}_{5} \\
14 \mathrm{RDBE}\end{array}$ & $\begin{array}{c}291.07 \\
{\left[-\mathrm{OCH}_{3}\right]} \\
\mathrm{C}_{18} \mathrm{H}_{11} \mathrm{O}_{4} \\
13 \mathrm{RDBE}\end{array}$ \\
\hline 15.98 & $\begin{array}{l}465.1191 \\
15 \mathrm{RDBE}\end{array}$ & Galtamycinone & $\begin{array}{c}449.12 \\
{[-\mathrm{O}]} \\
\mathrm{C}_{25} \mathrm{H}_{21} \mathrm{O}_{8}\end{array}$ & $\begin{array}{c}319.06 \\
{\left[-\mathrm{C}_{6} \mathrm{H}_{10} \mathrm{O}_{4}\right]} \\
\mathrm{C}_{19} \mathrm{H}_{11} \mathrm{O}_{5} \\
14 \mathrm{RDBE}\end{array}$ & $\begin{array}{c}303.07 \\
{[-\mathrm{OH}]} \\
\mathrm{C}_{19} \mathrm{H}_{11} \mathrm{O}_{4} \\
14 \mathrm{RDB}\end{array}$ \\
\hline
\end{tabular}




\subsection{Metabolomic Profiling of Cellular and Supernatant Extracts from Liquid Broth Cultures of EG49}

Metabolomic profiling was performed on methanol and acetone cellular extracts of three cell pellets and ethyl acetate extracts of their respective culture supernatants along with an extract obtained from the solid agar medium, as acquired from the cultivation protocol. The MS data were subjected to statistical analysis. PCA was then used to determine the differences of the extracts obtained from various culture conditions and extraction procedures. The degree of similarity between the ethyl acetate supernatant extracts from the four different culture media was higher than those of the methanol and acetone cellular extracts, which exhibited more dispersed and distinct features, as shown from the OPLS-DA map (Figure 4A). An S-plot was primed from the OPLS plot to determine the "end point" compounds, which define unique secondary metabolomes that differentiates the supernatant from the cellular extracts (Figure 4B and Table 2). Different sets of metabolites were extracted by the respective solvents, but with more anthraquinone derivatives being extracted from the supernatant with ethyl acetate than from the cells with acetone and methanol (Table 2).

Figure 4. Orthogonal partial least square-d iscriminant analysis (OPLS-DA) (A) and S-plot (B) of supernatant (red) vs. cellular extracts (blue). S (solid); LE (liquid ethyl acetate); LM (liquid methanol); BE (beads ethyl acetate; BM (beads methanol); XE (XAD ethyl acetate); XA (XAD acetone). $R_{2}=0.931, Q_{2}=0.995$ for OPLS-DA map.

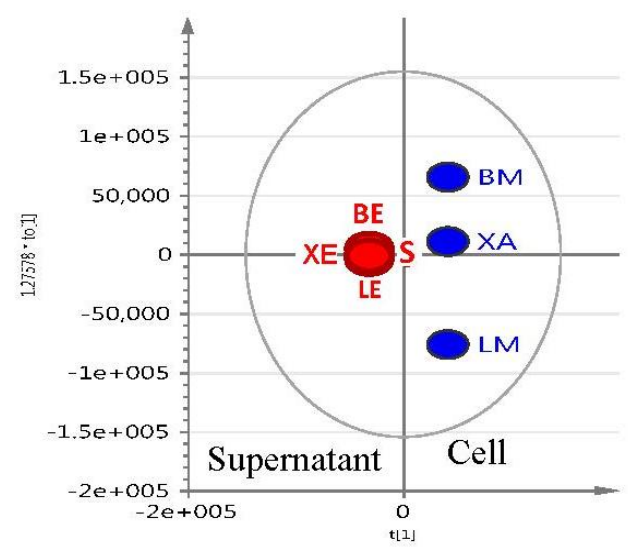

(A)

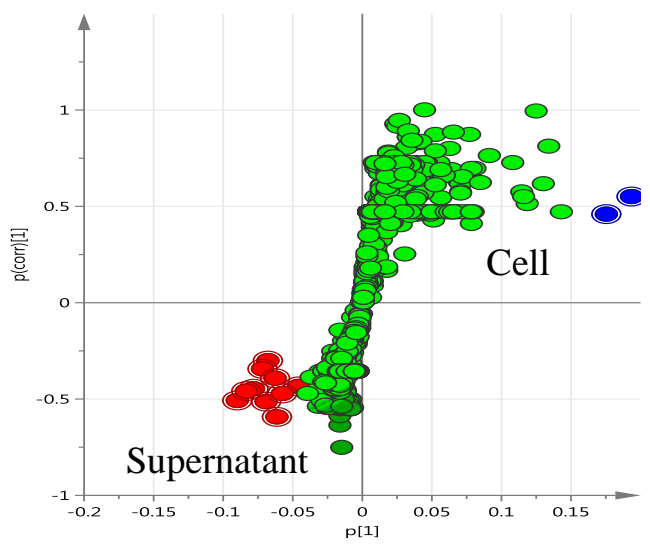

(B)

Table 2. The "end point" compounds defined as unique metabolites for every group, as shown on the S-plot in Figure 4B. ( $\mathrm{P}=$ positive mode; $\mathrm{N}=$ negative mode).

\begin{tabular}{lccccc}
\hline Solvent & \multicolumn{1}{l}{ Ionisation Mode } & MS $\boldsymbol{m} / \boldsymbol{z}$ & Rt (min) & Chemical Formula & Name \\
\hline EtOAc & $\mathrm{N}$ & 467.1350 & 8.27 & $\mathrm{C}_{25} \mathrm{H}_{24} \mathrm{O}_{9}$ & Atramycin A (12) \\
EtOAc & $\mathrm{P}$ & 469.1494 & 8.28 & $\mathrm{C}_{25} \mathrm{H}_{24} \mathrm{O}_{9}$ & Atramycin A (12) \\
EtOAc & $\mathrm{N}$ & 513.1404 & 8.28 & $\mathrm{C}_{26} \mathrm{H}_{25} \mathrm{O}_{11}$ & Unknown \\
EtOAc & $\mathrm{N}$ & 611.1768 & 8.98 & $\mathrm{C}_{31} \mathrm{H}_{32} \mathrm{O}_{13}(n e w) *$ & Actinosporin A (1) \\
EtOAc & $\mathrm{N}$ & 657.1828 & 10.50 & $\mathrm{C}_{32} \mathrm{H}_{34} \mathrm{O}_{15}$ & Elloramycin E (10) \\
EtOAc & $\mathrm{N}$ & 501.1407 & 10.76 & $\mathrm{C}_{25} \mathrm{H}_{26} \mathrm{O}_{11}(n e w) *$ & Actinosporin B (2) \\
EtOAc & $\mathrm{N}$ & 467.1350 & 15.13 & $\mathrm{C}_{25} \mathrm{H}_{24} \mathrm{O}_{9}$ & BE-12406-A \\
EtOAc & $\mathrm{N}$ & 449.1247 & 15.97 & $\mathrm{C}_{25} \mathrm{H}_{22} \mathrm{O}_{8}$ & Galtamycinone \\
MeOH & $\mathrm{N}$ & 377.0860 & 1.38 & $\mathrm{C}_{15} \mathrm{H}_{9} \mathrm{O}_{3} \mathrm{~N}_{10}$ & Unknown \\
MeOH & $\mathrm{N}$ & 452.2787 & 21.50 & $\mathrm{C}_{25} \mathrm{H}_{40} \mathrm{O}_{7}$ & Unknown \\
\hline
\end{tabular}

* Structures shown in Figure 5. 
Figure 5. Structures of actinosporins A (1) and B (2).

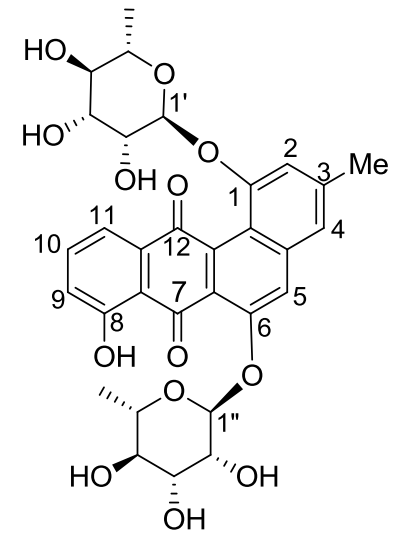

(1)<smiles>C[C@H]1O[C@H](Oc2cccc3c2C(=O)c2ccc4c(c2C3=O)[C@@H](O)[C@H](O)[C@](O)([14CH2]O)C4)[C@H](O)[C@@H](O)[C@@H]1O</smiles>

(2)

The extraction pattern was validated by subjecting the NMR spectral data (Figure 6A shows the scatter plot of NMR spectral data) to PCA (Figure 6C shows the 3D PCA-score plot and PCA-loading plot, respectively) and line plot (Figure 6D) obtained from the hierarchical clustering analysis (Figure 6E) of the PCA results performed on the NMR spectral data). Figure 6A indicated the presence of anthraquinone compounds to be highly concentrated in ISP2 broth with alginate beads, as shown by the dominance of red triangles $(\boldsymbol{\Delta}=\mathrm{BE})$ at $c a .7 .25 \mathrm{ppm}$, depicting aromatic proton signals on the anthraquinone moiety. The PCA results gave significant scores of 1.0 and 0.961 for cumulative $\mathrm{R}_{2} \mathrm{X}$ and $\mathrm{Q}_{2}$, respectively, which implied a very good prediction model for the variables. The 3D score plot of the different culture extracts showed the cellular XAD-acetone extract as an outlier, whilst the solid agar extract clustered with the methanolic cell extracts (Figure 6B). This could be explained by the different experimental procedures, where the cells were not separated from the agar media prior to extraction in contrast to those of the broth media. Line plots of the hierarchical clustering analysis (HCA) data (Figure 6E) revealed that the methanolic cellular extracts only contained primary polar metabolites (Figure 6D), which were mostly saccharides, as represented by the chemical shifts at ca. $5.0 \mathrm{ppm}$ and between 3.0 and $4.0 \mathrm{ppm}$. The signals from the ethyl acetate extracts showed a more even distribution of resonances between 1.0 and $8.5 \mathrm{ppm}$ in comparison to the methanolic extracts. The presence of signals between 3.0 and 5 ppm signified the presence of sugar moieties in the structure of metabolites found in the supernatant. The distribution of chemical shifts was reflected in the line plot (Figure 6D) obtained from the HCA dendrogram in Figure 6E. The aromatic region was dominated by signals belonging to the ethyl acetate supernatant fractions, which confirmed the presence of glycosidic quinone congeners in conformity with the dereplication study on the mass spectral and mass fragmentation data. The PCA and OPLS-DA of both the NMR and mass spectral data (Figures 3 and 4) consistently showed that the secondary metabolites of interest were secreted into the media. These results highlight the chemical diversity of the supernatants over the cell pellets in Actinokineospora sp. EG49 cultures. 
Figure 6. NMR-based dereplication of EG49 extracts: (A) Scatter plot of NMR spectral

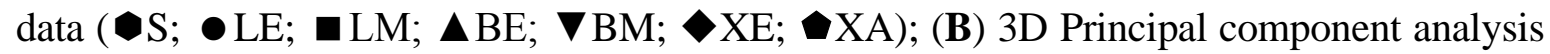
(PCA)-score plot; (C) PCA-loading plot of cellular (blue) vs. supernatant extracts (red); (D) Line plots obtained from the hierarchical clustering analysis of the PCA results as shown in (E). The primary observed ID (obs ID) is synonymous to the chemical shift in ppm.

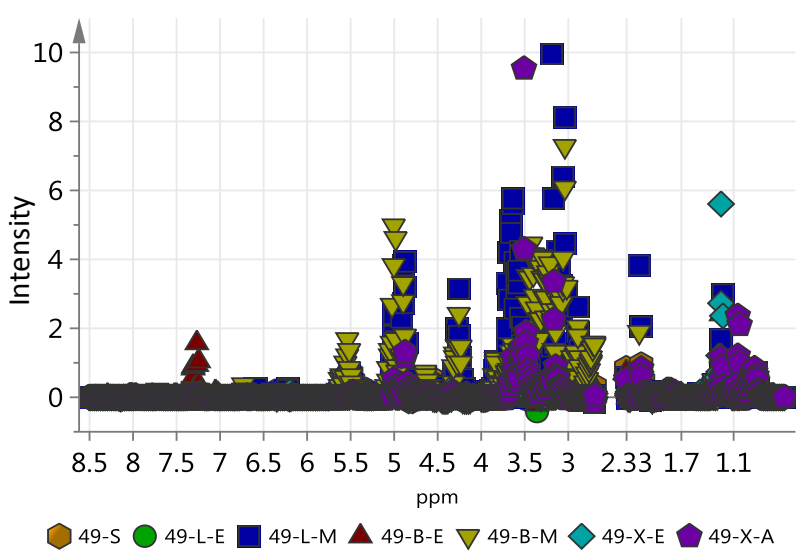

(A)

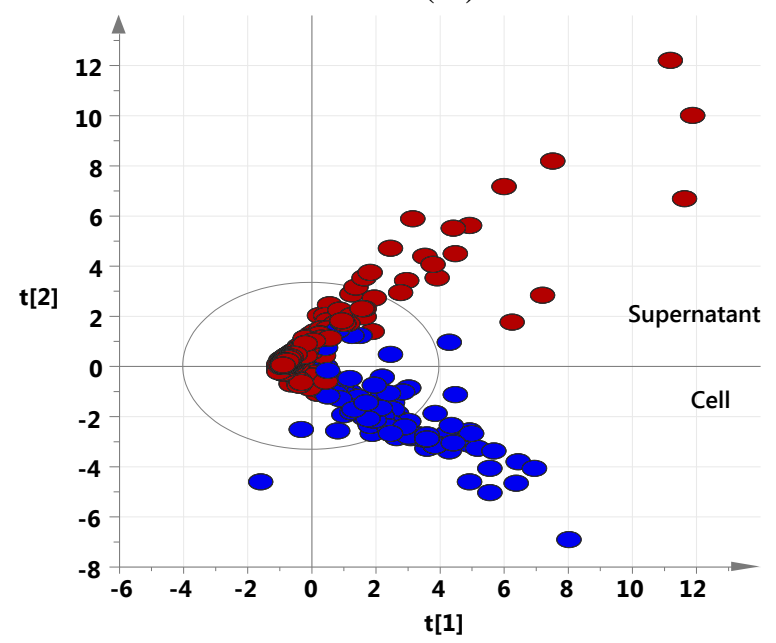

(C)

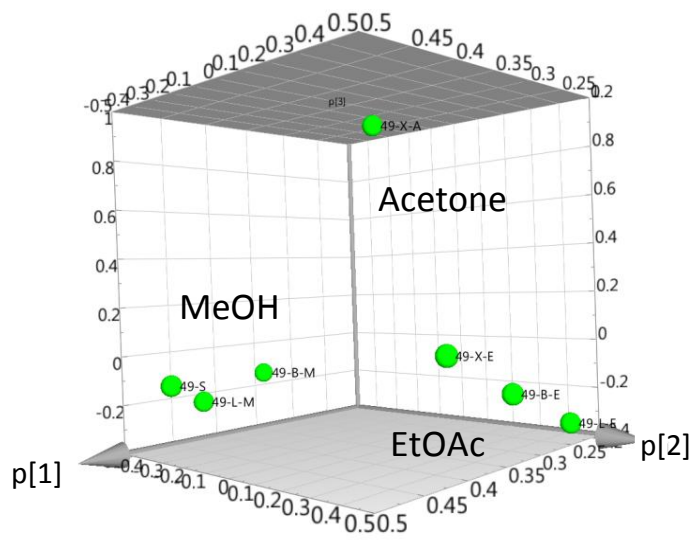

(B)

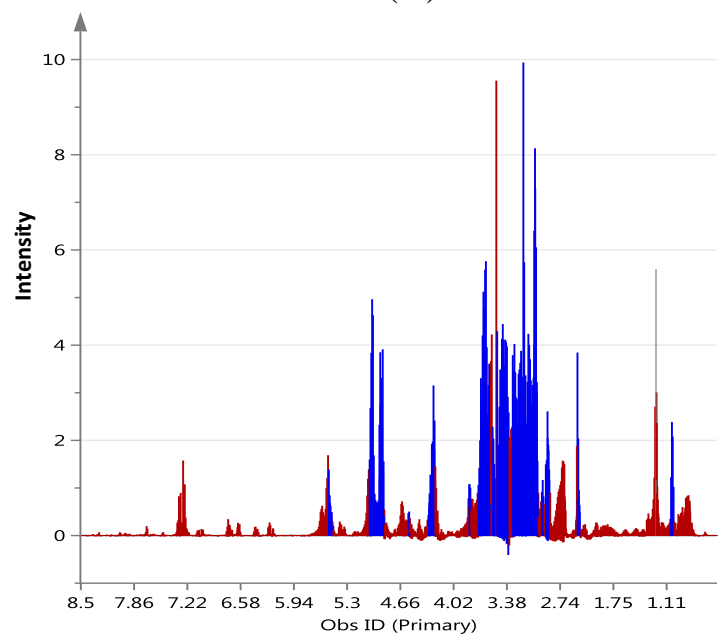

(D)

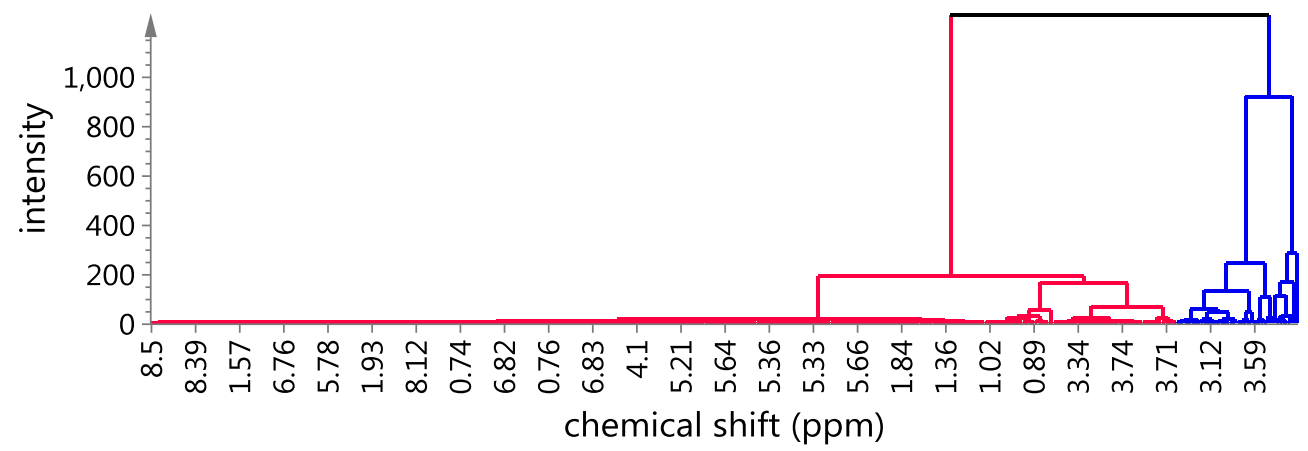

(E)

\subsection{Quantification of Actinosporin A in Four Different Culture Media}

To optimize production of the biologically active metabolites, dereplication was performed for microbial extracts prepared in triplicates obtained from four different growth media strategies (ISP2 agar, ISP2 broth, ISP2 broth with XAD, and alginate beads), as shown in Figures 7 and 8. Through the 
scatter- and S-plots (Figure 7), it was shown that unique metabolites were produced in respective culture media. The active antitrypanosomal compound actinosporin A $\left(\mathrm{m} / \mathrm{z} 611.1768[\mathrm{M}-\mathrm{H}]^{-}\right)$with retention time at 8.98 min was shown to be produced at the highest yield in liquid broth (LE) and alginate beads (BE) media (Figure 8), while it was produced in negligible amounts when XAD (XE) was used. There was a significant decrease of probable quinone congeners in the XAD media, which was indicated by the disappearance of dispersed components (represented by yellow dots) in the upper region of the diagonal for the ISP2 XAD extract when comparing the MZmine scatter plots in Figure 7A,B with Figure 7C.

Figure 7. Scatter plot (A-D, MZmine 2.10) and S-plot (D, E, SIMCA 13) of the mass spectral data for EG49 ethyl acetate extracts obtained from different culture methods. For the MZmine scatter plots on $(\mathbf{A}-\mathbf{C})$, dots nearer to or on the diagonal lines represent metabolites commonly found in both culture media, while the unique metabolites for each respective media appear above or below the diagonals on the direction of the respective axis representing each of the culture media. For the S-plots on (D-F), metabolites emerging at the center of the XY axis are the common metabolites for both media, while the unique metabolites for the respective medium are observed at the "end-points" of the sigmoidal curve. Probable quinone congeners eluting between 5 and $30 \mathrm{~min}$ are marked yellow on the scatter plots. The ion at $\mathrm{m} / \mathrm{z} 611.177$ with retention time of $8.98 \mathrm{~min}$ representing the antitrypanosomal active compound $\mathbf{1}$ is encircled in red.

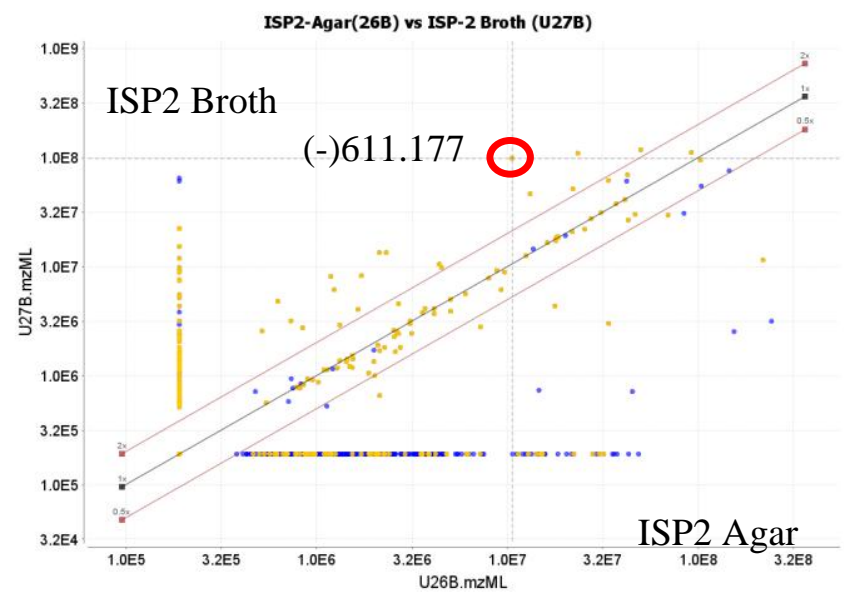

(A)

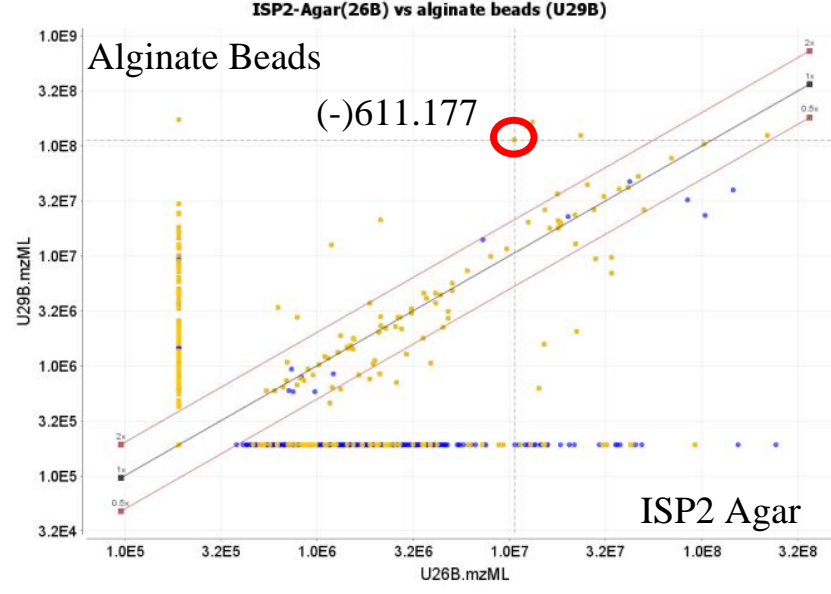

(B)

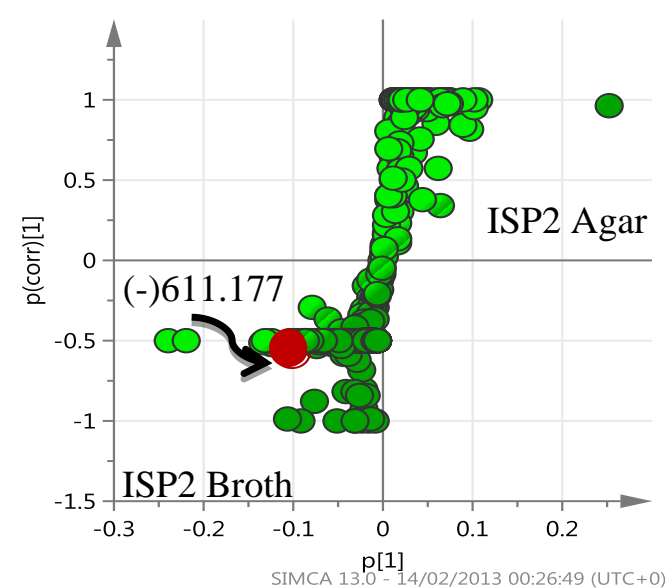

(D)

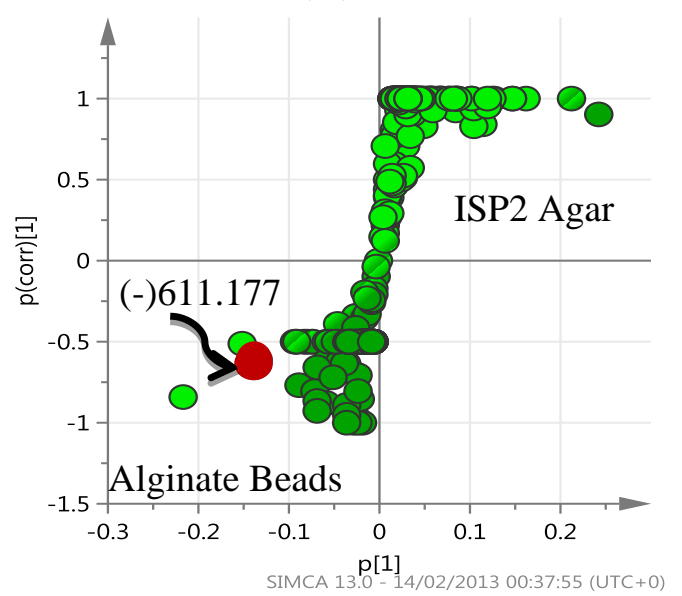

(E) 
Figure 7. Cont.

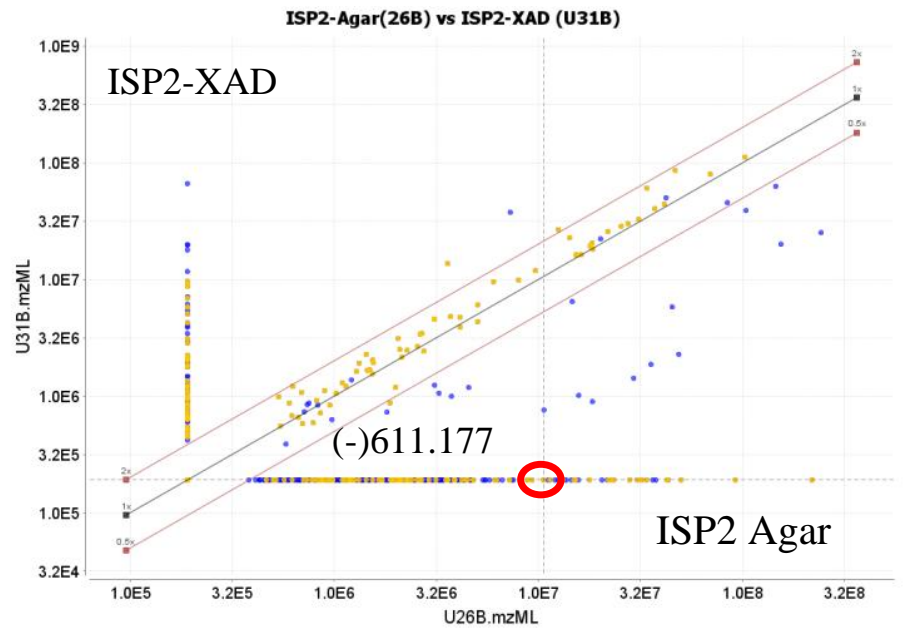

(C)

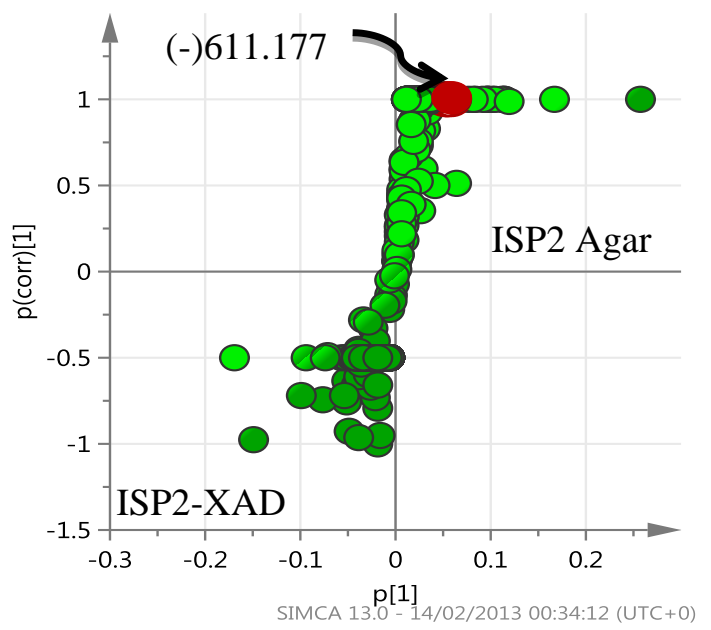

(F)

Figure 8. Scatter plots of the dereplicated mass spectral data of EG49 crude extracts obtained from four different growth media: $\mathrm{S}=\mathrm{ISP} 2$ agar, LE = ISP2 broth, BE = calcium alginate beads, and XE = ISP2 broth with XAD. Inset shows the contribution of actinosporin $\mathrm{A}$ in different culture media and extracts.

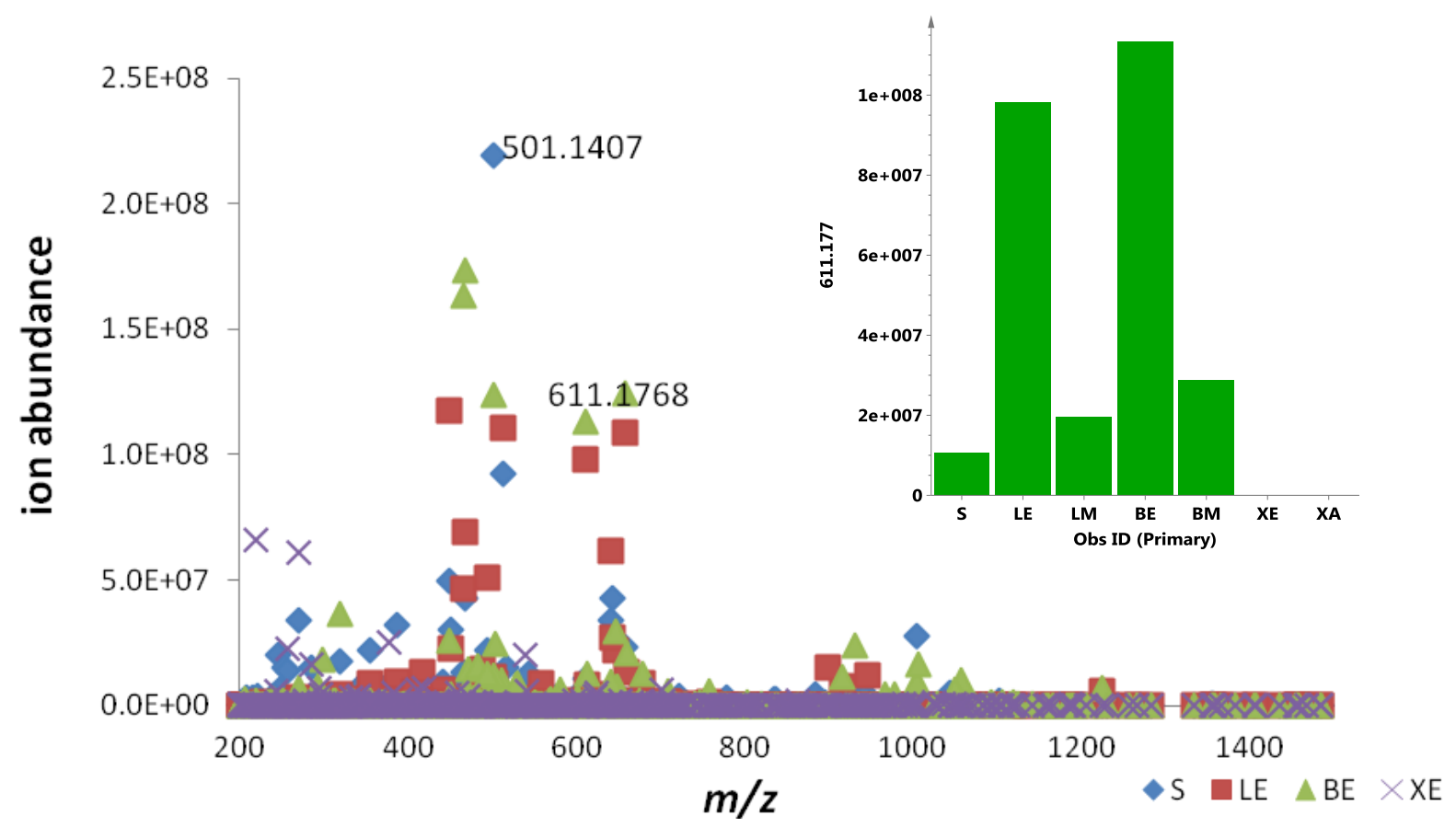

Analyzing the yield of ethyl acetate extract in $\% w / v$, ISP2 with calcium alginate bead (BE) gave the highest yield of $29.2 \%$, followed by ISP2 agar (S) with $11.9 \%$ and ISP2 broth (LE) with $8.9 \%$, while ISP2 with XAD (XE) showed the lowest yield of only $7.3 \%$ with extraction efficiencies of $79.9 \%$ for BE, $41.8 \%$ for $\mathrm{LE}$, and $35.6 \%$ for XE. In terms of the production of the antitrypanosomal active metabolite, as shown in Figure 8, the best concentration can be achieved at approximately 1.0E08 ion abundance, using either ISP2 broth (LE) or ISP2 with calcium alginate beads (BE). ISP2 with calcium alginate beads (BE) afforded higher biomass, but the ISP2 broth (LE) offered a more 
diverse range of interesting congeners, as shown in Figure 7A from the increase in the dispersal of the metabolomes on the $Y$ axis for the ISP2 broth extract.

\subsection{Bioassay-Guided Isolation and Structure Elucidation of the New Actinosporins A and B}

Crude extracts of the Actinokineospora sp. EG49 strain obtained from four fermentation approaches were tested against T. brucei brucei. Among all extracts, the ethyl acetate extract from the ISP2 broth culture (LE) was the most active and, therefore, was selected to pursue bioassay-guided isolation of the bioactive metabolites. The antitrypanosomally active ethyl acetate extract was chromatographed on silica gel by gradient elution with $\mathrm{CHCl}_{3}$ and $\mathrm{MeOH}$. Fractions exhibiting a growth inhibition of T. brucei brucei of more than $50 \%$ were considered active and subjected to further isolation work (see Figure S3 in Supplementary Information for schematic diagram). The bioactive semi-polar fraction eluting with 60:40 of $\mathrm{CHCl}_{3}: \mathrm{MeOH}$ was further subjected to gel filtration on Sephadex LH-20 by gradient elution with $\mathrm{MeOH}: \mathrm{H}_{2} \mathrm{O}$, commencing with $20 \% \mathrm{MeOH}$ culminating to $100 \% \mathrm{MeOH}$. The LH-20 fraction eluting at 60:40 MeOH: $\mathrm{H}_{2} \mathrm{O}$ exhibited antitrypanosomal activity and final purification was accomplished on reversed-phase HPLC to yield two pure compounds $\mathbf{1}$ and $\mathbf{2}$, named actinosporins $\mathrm{A}$ and $\mathrm{B}$, respectively (Figure 5). Actinosporin A showed a molecular formula of $\mathrm{C}_{31} \mathrm{H}_{32} \mathrm{O}_{13}$ by HR-ESIMS (ORBITRAP) analysis (found at $\mathrm{m} / z 613.1915[\mathrm{M}+\mathrm{H}]^{+}$), with 16 degrees of unsaturation. HRFT-tandem MS of the molecular ion peak at $m / z 611.1768[\mathrm{M}-\mathrm{H}]^{-}$for $\mathrm{C}_{31} \mathrm{H}_{31} \mathrm{O}_{13}$ gave fragment ion peaks at $\mathrm{m} / \mathrm{z} 465.1177\left(\mathrm{C}_{25} \mathrm{H}_{21} \mathrm{O}_{9}\right.$, calcd: 465.1186$)$ and $319.0607\left(\mathrm{C}_{19} \mathrm{H}_{11} \mathrm{O}_{5}\right.$, calcd: 319.0601), and revealed the successive loss of two saccharide units, since the subtracted molecular formula was $\mathrm{C}_{6} \mathrm{H}_{11} \mathrm{O}_{4}$. This molecular ion peak at $m / z, 611.1768$ was also found in the above list of unidentified compounds during the dereplication study. The presence of two anomeric protons at $\delta_{\mathrm{H}} 5.48$ and 5.66 along with 2 methyl doublets in the aliphatic region indicated the presence of two 6-deoxy rhamnose moieties and further confirmed the characteristic chemical shifts for the anomeric carbons at 99.0 and $99.6 \mathrm{ppm}$, which suggested the glycosidic nature of the compound. The IR spectrum showed bands at 3389, 3206, $1677 \mathrm{~cm}^{-1}$, thus indicating the possible occurrence of carbonyl and hydroxyl functionalities.

The ${ }^{1} \mathrm{H}-{ }^{1} \mathrm{H}-\mathrm{COSY}$ spectrum indicated two substructures, along with one methine at $\delta_{\mathrm{H}} 7.69$ that appeared as a singlet. The first substructure involved two doublets at $\delta 7.21(\mathrm{~J}=7.3 \mathrm{~Hz})$ and 7.52 $(J=7.3 \mathrm{~Hz}) \mathrm{ppm}$, and an apparent triplet at $\delta 7.66(J=7.3 \mathrm{~Hz})$, which can be attributed to a 1,2,3-trisubstituted aromatic system. The second substructure consisted of two meta-coupled aromatic protons at $\delta_{\mathrm{H}} 7.19$ and 7.26. A singlet of an aromatic-bound methyl group was observed at $\delta_{\mathrm{H}} 2.47$, which coupled to the two meta-coupled aromatic resonances. The ${ }^{13} \mathrm{C}$ NMR spectrum displayed two quinone carbonyls $\left(\delta_{C} 186.2\right.$ and 187.5), two anomeric carbons $\left(\delta_{C} 99.0\right.$ and 99.6), eight oxymethine carbons $\left(\delta_{\mathrm{C}} 69.6,69.9,70: 4,70.6,70.7,70.9,72.4,72.5\right)$, three tertiary carbinols $\left(\delta_{\mathrm{C}} 152.3,153.9\right.$, 161.2), five shielded $\mathrm{sp}^{2}$ methine carbons $\left(\delta_{\mathrm{C}} 112.2,116.9,117.1,119.6,122.6\right)$, and a distinct signal at $\delta_{\mathrm{C}} 20.8$ consistent for an aromatic methyl. Analysis of the COSY, HSQC, and HMBC data (Table 3) showed that the core of the compound had a benz $(\alpha)$ anthraquinone backbone, which is characteristic for the angucycline group. ROESY (rotating-frame nuclear Overhauser effect correlation spectroscopy); and HMBC revealed that the two sugars were O-linked to the aglycone at C-1 $\left({ }^{3} J_{\mathrm{C}-\mathrm{H}}\right.$ correlation between $\delta_{\mathrm{H}-1}, 5.48$ with $\left.\delta_{\mathrm{C}-1} 153.9\right)$ and the other at C-6 $\left({ }^{3} J_{\mathrm{C}-\mathrm{H}}\right.$ correlation between $\mathrm{H}-1^{\prime \prime}$, 
$\delta_{\mathrm{H}-1} 5.66$ with C-6, $\delta_{\mathrm{C}}$ 152.3). In addition, ROESY correlations were detected between $\mathrm{H}-1^{\prime}$ and $\mathrm{H}-2$, as well as between $\mathrm{H}-1$ " and $\mathrm{H}-5$, confirming the glycosidation at $\mathrm{C}-1$ and $\mathrm{C}-6$, respectively. COSY data deduced the spin systems for the two rhamnose moieties. The two anomeric protons of the two sugars appeared as broad singlets, indicating that the anomeric configuration of the two sugar moieties were $\alpha$-glycosidically linked. Further confirmation of the equatorial orientation of the anomeric protons on the two rhamnose residues was established via measurement of the one-bond ${ }^{13} \mathrm{C}-{ }^{1} \mathrm{H}$ couplings $\left({ }^{1} J_{\mathrm{CH}}\right)$. In a ${ }^{13} \mathrm{C}$-coupled HSQC experiment, the ${ }^{1} J_{\mathrm{CH}}$ for the two anomeric protons resonating at $\delta_{\mathrm{H}} 5.48$ and 5.66 were found to be 172.1 and $172.9 \mathrm{~Hz}$, respectively, consistent with an $\alpha$-configuration. The relative configuration of the rhamnose residues in $\mathbf{1}$ was determined by their coupling constants and ROESY data at $600 \mathrm{MHz}$ with $t_{\mathrm{m}}=400 \mathrm{~ms}$. For sugar A, the large coupling constant for the proton $\mathrm{H}-4^{\prime}(J=9.4 \mathrm{~Hz})$, resulting from diaxial correlations, showed that $\mathrm{H}-3^{\prime}, \mathrm{H}-4^{\prime}$, and $\mathrm{H}-5^{\prime}$ had axial orientations. Furthermore, the small coupling constant between $\mathrm{H}-3^{\prime}$ and $\mathrm{H}-2^{\prime}$ $(J=3.4 \mathrm{~Hz})$ showed that $\mathrm{H}-2^{\prime}$ was oriented equatorially. Thus, ${ }^{1} \mathrm{H}$ NMR coupling constant analysis, COSY and ROESY experiments showed that compound $\mathbf{1}$ consists of L-rhamnose, which is the naturally occurring isomer among natural products. The relative configuration of sugar B was the same as sugar A, based on the same spectroscopic information. Acid hydrolysis of $\mathbf{1}$ was performed to yield L-rhamnose, which was confirmed via TLC and comparison to authentic samples. Based on the detailed analysis of the NMR spectra, the structure of compound $\mathbf{1}$ was determined to be 8-hydroxy-3-methylbenz[ $\alpha]$ anthracene-7,12-dione-1- $O$ - $\alpha$-L-rhamnopyranose- $6-O$ - $\alpha$-L-rhamnopyranoside, which had not been previously reported. It was designated the trivial name actinosporin $\mathrm{A}$.

Table 3. NMR data of actinosporin A (1), measured in $\mathrm{CD}_{3} \mathrm{OD}-d_{4}\left({ }^{1} \mathrm{H}\right.$ : $600 \mathrm{MHz}$; $\left.{ }^{13} \mathrm{C}: 150 \mathrm{MHz}\right)$.

\begin{tabular}{|c|c|c|c|c|c|c|}
\hline Position C/H No. & $\delta_{\mathrm{H}}, \operatorname{Mult}(J$ in Hz$)$ & COSY & $\boldsymbol{\delta}_{\mathrm{C}}$ & Mult & $\operatorname{HMBC}\left(\delta_{\mathrm{H}}\right.$ to $\left.\delta_{\mathrm{C}}\right)$ & ROESY \\
\hline 1 & & & 153.9 & $\mathrm{C}$ & & \\
\hline 2 & $7.19, \mathrm{~s}$ & $\mathrm{H}-3-\mathrm{CH}_{3}$ & 112.2 & $\mathrm{CH}$ & $\begin{array}{l}\mathrm{C}-1, \mathrm{C}-3, \mathrm{C}-3-\mathrm{CH}_{3} \\
\mathrm{C}-4, \mathrm{C}-12 \mathrm{a}, \mathrm{C}-12 \mathrm{~b}\end{array}$ & $\begin{array}{l}\mathrm{H}-3-\mathrm{CH}_{3}, \\
\mathrm{H}-1 \mathrm{~A}\end{array}$ \\
\hline 3 & & & 142.0 & $\mathrm{C}$ & & \\
\hline 3- $\mathrm{CH}_{3}$ & $2.47, \mathrm{~s}$ & $\mathrm{H}-2, \mathrm{H}-4$ & 20.8 & $\mathrm{CH}_{3}$ & $\mathrm{C}-2, \mathrm{C}-3, \mathrm{C}-4$ & \\
\hline 4 & $7.26, \mathrm{~s}$ & $\mathrm{H}-3-\mathrm{CH}_{3}$ & 119.6 & $\mathrm{CH}$ & $\begin{array}{c}\mathrm{C}-2, \mathrm{C}-3-\mathrm{CH}_{3}, \\
\mathrm{C}-4 \mathrm{a}, \mathrm{C}-12 \mathrm{~b}\end{array}$ & $\begin{array}{l}\mathrm{H}-3-\mathrm{CH}_{3}, \\
\quad \mathrm{H}-5\end{array}$ \\
\hline $4 a$ & & & 138.9 & $\mathrm{C}$ & & \\
\hline 5 & $7.69, \mathrm{~s}$ & & 116.9 & $\mathrm{CH}$ & $\begin{array}{c}\text { C-4, C-6, C-6a, } \\
\text { C-12b }\end{array}$ & $\begin{array}{l}\mathrm{H}-4, \mathrm{H}-1 \mathrm{~B}, \\
\quad \mathrm{H}-5 \mathrm{~B}\end{array}$ \\
\hline 6 & & & 152.3 & $\mathrm{C}$ & & \\
\hline $6 \mathbf{a}$ & & & 124.0 & $\mathrm{C}$ & & \\
\hline 7 & & & 186.2 & $\mathrm{C}$ & & \\
\hline $7 \mathbf{a}$ & & & 115.7 & $\mathrm{C}$ & & \\
\hline 8 & & & 161.2 & $\mathrm{C}$ & & \\
\hline 9 & $7.21, \mathrm{~d}(7.3)$ & $\mathrm{H}-10, \mathrm{H}-11$ & 122.6 & $\mathrm{CH}$ & C-7a, C-11, C-10 & \\
\hline 10 & 7.66, t (7.3) & H-9, H-11 & 136.1 & $\mathrm{CH}$ & C-8, C-11, C-11a & \\
\hline 11 & $7.52, \mathrm{~d}(7.3)$ & H-9, H-10 & 117.1 & $\mathrm{CH}$ & $\begin{array}{l}\text { C-7, C-7a, C-9, } \\
\text { C-10, C-12 }\end{array}$ & \\
\hline $11 \mathrm{a}$ & & & 135.5 & $\mathrm{C}$ & & \\
\hline
\end{tabular}


Table 3. Cont.

\begin{tabular}{|c|c|c|c|c|c|c|}
\hline 12 & & & 187.5 & $\mathrm{C}$ & & \\
\hline $12 a$ & & & 140.0 & $\mathrm{C}$ & & \\
\hline $12 b$ & & & 116.1 & $\mathrm{C}$ & & \\
\hline $\mathbf{1}^{\prime}$ & 5.48 , brs & H-2' & 99.6 & $\mathrm{CH}$ & $\mathrm{C}-1, \mathrm{C}-2^{\prime}, \mathrm{C}-5^{\prime}$ & $\mathrm{H}-2$ \\
\hline $2^{\prime}$ & $4.05, \mathrm{~s}$ & $\mathrm{H}-1^{\prime}, \mathrm{H}-3^{\prime}$ & 70.4 & $\mathrm{CH}$ & $\mathrm{C}-3^{\prime}, \mathrm{C}-4^{\prime}$ & \\
\hline $3^{\prime}$ & $\begin{array}{l}3.80, \mathrm{dd} \\
(9.4,3.4)\end{array}$ & $\mathrm{H}-2^{\prime}, \mathrm{H}-4^{\prime}$ & 70.9 & $\mathrm{CH}$ & $\mathrm{C}-4^{\prime}, \mathrm{C}-5^{\prime}$ & \\
\hline $4^{\prime}$ & $3.48, \mathrm{t}(9.4)$ & H-3', H-5' & 72.4 & $\mathrm{CH}$ & $\mathrm{C}-3^{\prime}, \mathrm{C}-5^{\prime}, \mathrm{C}-6^{\prime}$ & H-6' \\
\hline $5^{\prime}$ & $3.76, \mathrm{~m}$ & H-6 & 69.6 & $\mathrm{CH}$ & C- $6^{\prime}$ & H-3' \\
\hline $6^{\prime}$ & $1.25, \mathrm{~d}(6.3)$ & H-5' & 16.5 & $\mathrm{CH}_{3}$ & $C-5^{\prime}, C-4^{\prime}$ & \\
\hline $1^{\prime \prime}$ & 5.66 , brs & $\mathrm{H}-2^{\prime \prime}$ & 99.0 & $\mathrm{CH}$ & C-8, C-5", C-4" & $\mathrm{H}-5$ \\
\hline $2^{\prime \prime}$ & $4.22, \mathrm{~d}(3.4)$ & H-1", H-3" & 70.6 & $\mathrm{CH}$ & C-3", C-4" & \\
\hline $3^{\prime \prime}$ & $4.25, \mathrm{~s}$ & H-2", H-4" & 70.7 & $\mathrm{CH}$ & C-4" & $\mathrm{H}-5^{\prime \prime}$ \\
\hline $4 "$ & $3.53, \mathrm{t}(9.2)$ & H-3", H-5" & 72.5 & $\mathrm{CH}$ & $\mathrm{C}-2^{\prime \prime} \mathrm{C}-3^{\prime \prime}, \mathrm{C}-6^{\prime \prime}$ & \\
\hline $5^{\prime \prime}$ & $3.74, \mathrm{~m}$ & H-6" & 69.9 & $\mathrm{CH}$ & C-3", C-4", C-6" & \\
\hline $6^{\prime \prime}$ & $1.27, \mathrm{~d}(6.2)$ & $\mathrm{H}-5^{\prime \prime}$ & 16.6 & $\mathrm{CH}_{3}$ & C-4", C-5" & \\
\hline
\end{tabular}

Note: s (singlet); d (doublet); $\mathrm{t}$ (triplet); brs (broad singlet).

Actinosporin B was obtained as an orange oil and the mass spectrum revealed the occurrence of $\mathrm{m} / \mathrm{z} 501.1402$ in negative mode and $\mathrm{m} / \mathrm{z} 503.1554$ in positive mode $\left(\mathrm{C}_{25} \mathrm{H}_{26} \mathrm{O}_{11}\right)$. This pseudomolecular ion peak was found in the identified compounds list (Table 1) and the structure of 2 was studied by comparing the mass spectral and NMR data with the known compound hit 13, which was found in AntiBase and proved that the isolated compound was different from compounds reported in the literature. It was of interest to us to elucidate this compound due to its exclusive occurrence in the ISP2 solid agar extract only.

The UV spectrum exhibited a maximum absorption at $254 \mathrm{~nm}$, while a shift of the bands from 310 to $379 \mathrm{~nm}$ indicated loss of aromaticity on Ring A. The ${ }^{1} \mathrm{H}$ NMR spectrum showed the presence of aromatic protons with peaks from $\delta_{\mathrm{H}} 7.62$ to 7.96 , which all integrated for one proton each. The COSY spectrum revealed two spin systems in the aromatic region. Correlation between the "pseudo-triplet" at $\delta_{\mathrm{H}} 7.86$ and two doublets at $\delta_{\mathrm{H}} 7.96$ and 7.71 indicated an $\mathrm{ABC}$ spin system. The correlation of two ortho-coupled doublets at $\delta_{\mathrm{H}} 7.80$ and 7.62 suggested an $\mathrm{AB}$ aromatic spin system. The parent structure was determined to be a quinone with one aromatic $\mathrm{ABC}$ system (ring D) and another $\mathrm{AB}$ system (ring B). The presence of a rhamnose unit was also detected from the COSY spectrum with the characteristic methyl $6.3 \mathrm{~Hz}$ doublet at $\delta_{\mathrm{H}} 1.10$, which correlated with a proton at $\delta_{\mathrm{H}} 3.53$ as well as the broad singlet at $\delta_{\mathrm{H}} 5.65$, resulting in a cross peak with a signal at $\delta_{\mathrm{H}} 3.35$. Attachment of the rhamnose was deduced to be on C-8 as the proton doublet at C-9 was highly deshielded, as observed in similarly substituted analogues, such as landomycin and atramycin.

Two well-resolved geminal methylene doublets at $\delta_{\mathrm{H}} 3.01$ and 2.90 with ${ }^{2} J$ of $13.4 \mathrm{~Hz}$ were assigned at position 4 due to the benzylic nature of the deshielded chemical shifts as well as their being adjacent to a stereogenic center at C-3. The hydroxyl methylene protons $\mathrm{H}-13 \mathrm{~A}$ and $\mathrm{H}-13 \mathrm{~B}$ situated on the quaternary chiral carbon C-3A were assigned to the broad doublet signal at $\delta_{\mathrm{H}} 4.93$ coupling with its germinal partner proton found underneath the solvent peak at $\delta_{\mathrm{H}} 3.35$ as determined by COSY. The 
hydroxylated broad methine doublet at $\delta_{\mathrm{H}} 5.12$ correlated with the broad singlet peak at $\delta_{\mathrm{H}} 4.01$ and were assigned to be $\mathrm{H}-1$ and $\mathrm{H}-2$, respectively. For a small yield of less than $1 \mathrm{mg},{ }^{1} \mathrm{H}-{ }^{1} \mathrm{H}-\mathrm{COSY}$, HSQC/HMQC and HMBC NMR spectral data were collected. However, the HSQC and HMQC did not give any good resolution for further data interpretation. Partial carbon assignments can be deduced from the HMBC data. The methylene doublets at $\delta_{\mathrm{H}} 3.06$ and 2.90 for $\mathrm{H}-4 \mathrm{~A}$ and $\mathrm{H}-4 \mathrm{~B}$ on ring $\mathrm{A}$ correlated with carbon signals at $\delta_{\mathrm{C}} 71.7,72.5,116.0133 .3$, and 140.7 for positions $2,3,12 \mathrm{~b}, 12 \mathrm{a}$ $\left({ }^{4} J_{\omega}\right)$, and 4 a respectively, further indicating the loss of unsaturation on ring A. On the other hand, the ortho doublet at $\delta_{\mathrm{H}} 7.62$ for $\mathrm{H}-5$ on ring $\mathrm{B}$ exhibited cross peaks with $\delta_{\mathrm{C}}$ at 42.7, 116.0, 133.3, and $181.0\left({ }^{4} J_{\omega}\right)$, for positions $4,12 \mathrm{~b}, 6 \mathrm{a}$, and 7 , respectively. On ring $\mathrm{D}$, cross peaks were observed between the ortho doublet at $\delta_{\mathrm{H}} 7.70$ for $\mathrm{H}-9$ and $\delta_{\mathrm{C}}$ at 122.0 for C-11. The ortho triplet at $\delta_{\mathrm{H}} 7.87$ for $\mathrm{H}-10$ had a correlation with $\delta_{\mathrm{C}}$ at 135.6 for C-11a and 156.9 for C-8. The 4 ppm upfield shift of C-8 in comparison to compound $\mathbf{1}$ was additional evidence on the attachment of rhamnose on ring $\mathrm{D}$ which was also further confirmed by the correlation of the anomeric proton at $\delta_{\mathrm{H}} 5.65$ with $\delta_{\mathrm{C}} 156.9$. The methyl doublet at $\delta_{\mathrm{H}} 1.10$ had cross peaks with the oxymethine carbons at $\delta_{\mathrm{C}} 71.4\left(\mathrm{C}-3^{\prime}\right)$ and $71.5\left(\mathrm{C}-4^{\prime}\right)$, while the anomeric proton correlated with signals at $\delta_{\mathrm{C}} 70.5\left(\mathrm{C}-2^{\prime}\right)$ and $64.0\left(\mathrm{C}-5^{\prime}\right)$.

High resolution FT tandem MS was performed obtaining a fragment ion at $\mathrm{m} / \mathrm{z} 399.1079$ $\left[\mathrm{M}-\mathrm{C}_{4} \mathrm{H}_{6} \mathrm{O}_{3}\right]^{-}$which implied a cross-ring cleavage comparable to a glycan unit [47] and confirmed the presence of a highly hydroxylated saturated ring A. High resolution mass spectral data of the fragment ions verified the presence of four hydroxyl substituents on ring A as shown in Figure 9. Further fragmentation of the ion at $\mathrm{m} / \mathrm{z}, 399.1079$ afforded an ion peak at $\mathrm{m} / \mathrm{z} 253.0502$ indicating the loss of a saccharide unit as in actinosporin A. The structure was determined as 1,2,3-trihydroxy-3-(hydroxymethyl)-8-rhamnosyl-benz[ $\alpha]$ anthracene-7,12-dione and assigned the trivial name actinosporin $\mathrm{B}$.

Figure 9. (A) Fragmentation of actinosporin B; (B) HMBC correlation of actinosporin B. Arrows are from proton $\left({ }^{1} \mathrm{H}\right)$ to carbon $\left({ }^{13} \mathrm{C}\right)$.

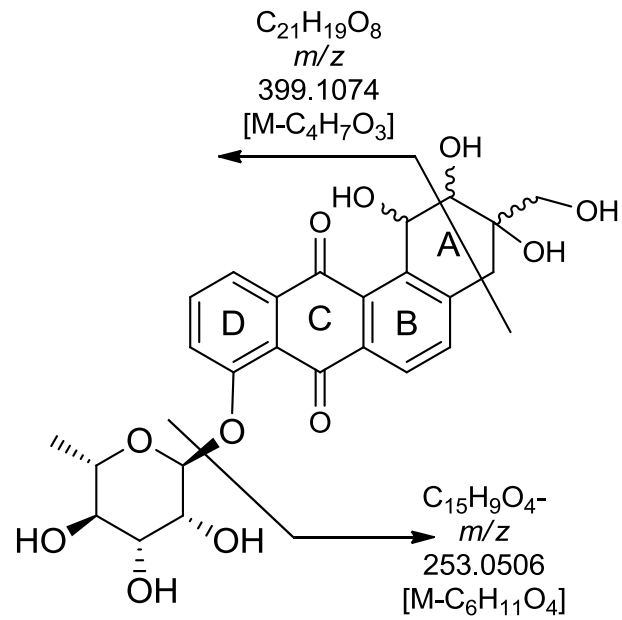

(A)

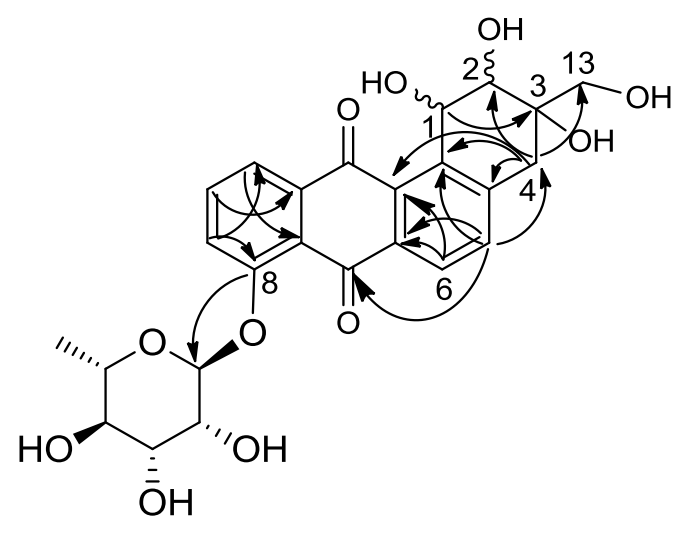

(B)

Actinosporins A and B were tested against the parasites Leishmania major, Trypanosoma brucei brucei, and Plasmodium falciparum, and for cytotoxicity against J774.1 macrophages to verify the original activity of the extract. Antitrypanosomal activity after 48 and $72 \mathrm{~h}$ was detected for actinosporin A, 
which exhibited $I C_{50}$ values of 15.47 and $16.44 \mu \mathrm{M}$, respectively, with no cytotoxicity against $\mathrm{J} 774.1$ macrophages $\left(I C_{50}\right.$ of $\left.>200 \mu \mathrm{M}\right)$. However, actinosporin B was found to be inactive against T. brucei. Human African trypanosomiasis, also known as sleeping sickness, is a fatal disease caused by T. brucei affecting mostly the people living in tropical and subtropical regions of the world [46]. The increasing resistance to current therapies and the undesirable side-effects of existing drugs necessitates the development of new, safer, and more potent alternatives to combat this neglected disease. Natural products will continue to play a vital role in the search for new antitrypanosomal drugs $[48,49]$.

\section{Experimental Section}

\subsection{Fermentation Approaches}

\subsubsection{Solid Culture}

The Actinokineospora strain EG49 was fermented for 7 days at $30{ }^{\circ} \mathrm{C}$ on 10 ISP2 agar plates. Colonies and agar were cut into small pieces and macerated twice with $500 \mathrm{~mL}$ ethyl acetate under continuous shaking at $150 \mathrm{rpm}$ (Edmund Bühler, Hechingen, Germany) overnight. Ethyl acetate marc was filtered (Whatman filter paper, Roth) and the combined filtrates (coded as Solid ethyl acetate) were dried with a rotary evaporator (Heidolph, Schwabach, Germany) under vacuum. The extracts were concentrated under vacuum and stored at $4{ }^{\circ} \mathrm{C}$ for chromatographic analysis.

\subsubsection{Liquid Culture}

One $2 \mathrm{~L}$ Erlenmeyer flask containing $1.5 \mathrm{~L}$ of ISP2 medium was inoculated with $1 \mathrm{~mL}$ of an exponentially growing five-day cell culture of Actinokineospora strain EG49 and kept in culture under shaking at $150 \mathrm{rpm}$ and $30{ }^{\circ} \mathrm{C}$ for 7 days. After cultivation and filtration, the supernatant was extracted with ethyl acetate $(2 \times 750 \mathrm{~mL})$. The cells were macerated in $500 \mathrm{~mL}$ methanol and shaken for $3 \mathrm{~h}$ (150 rpm), and subsequently filtered. The extracts (coded as Liquid ethyl acetate and Liquid methanol, respectively) were concentrated under vacuum and stored at $4{ }^{\circ} \mathrm{C}$ prior to further analytical and isolation work.

\subsubsection{Liquid Culture with XAD}

One $2 \mathrm{~L}$ Erlenmeyer flask containing $1.5 \mathrm{~L}$ of ISP2 medium supplemented with $20 \mathrm{~g} / \mathrm{L}$ XAD-16 (Sigma-Aldrich, Dorset, UK) was inoculated with $1 \mathrm{~mL}$ of an exponentially growing five-day cell culture of Actinokineospora strain EG49 and kept in culture under shaking at $150 \mathrm{rpm}$ at $30{ }^{\circ} \mathrm{C}$ for 7 days. After cultivation and filtration, the supernatant was extracted with ethyl acetate $(2 \times 750 \mathrm{~mL})$. The cells and XAD were shaken with double volumes $(2 \times 750 \mathrm{~mL})$ of acetone for $3 \mathrm{~h}$, and subsequently filtered. The extracts (coded as XAD ethyl acetate and XAD acetone) were concentrated using a vacuum rotary evaporator and stored at $4{ }^{\circ} \mathrm{C}$ prior to analysis. Only cells grown in XAD resin were subject to acetone extraction. 


\subsubsection{Liquid Culture with Calcium Alginate Beads}

An exponentially growing five-day cell culture of Actinokineospora strain EG49 (500 mL) was collected by centrifugation at $7155 \times g$ for $10 \mathrm{~min}$ and the pellet was mixed with $4 \%(\mathrm{w} / \mathrm{v})$ sodium alginate, containing HEPES buffer $(1 \%)$. The sodium alginate mixture was slowly dropped with a $5 \mathrm{~mL}$ syringe into a $1.5 \%(w / v) \mathrm{CaCl}_{2}$ solution at $4{ }^{\circ} \mathrm{C}$ under stirring. The produced beads were washed three times with sterile distilled water. Three hundred $\mathrm{mL}$ calcium alginate beads with immobilized bacteria were transferred to a 2 L Erlenmeyer flask, containing 1.2 L ISP2 medium and incubated at $30{ }^{\circ} \mathrm{C}$ under shaking $(150 \mathrm{rpm})$ for 7 days. After filtration, the beads were extracted by shaking with methanol for $3 \mathrm{~h}$, followed by filtration. The supernatant was extracted with ethyl acetate $(2 \times 750 \mathrm{~mL})$. The extracts (coded as Beads ethyl acetate and Beads methanol) were concentrated under vacuum and stored at $4{ }^{\circ} \mathrm{C}$ prior to further analysis. Blank controls, devoid of bacteria, were used for each approach. The control liquid media were extracted only with ethyl acetate.

\subsection{General Procedure for Dereplication Study Using MS and NMR Data}

Extracts of $1 \mathrm{mg} / \mathrm{mL}$ in $\mathrm{MeOH}$ were analyzed in triplicates on an Accela HPLC (Thermo Fisher Fisher Scientific, Bremen, Germany), and detected at 280 and $360 \mathrm{~nm}$ with a UV detector and an Exactive-Orbitrap high resolution mass spectrometer (Thermo Fisher Scientific, Bremen, Germany). Media blanks were prepared for comparison reasons. The HPLC column was an ACE (Hichrom Limited, Reading, UK) C18, $75 \mathrm{~mm} \times 3.0 \mathrm{~mm}, 5 \mu \mathrm{m}$ column. The mobile phase consisted of purified water (A) and acetonitrile (B) with $0.1 \%$ formic acid in each solvent. The gradient program started with $10 \% \mathrm{~B}$ and $\mathrm{B}$ was increased linearly in $30 \mathrm{~min}$ to $100 \% \mathrm{~B}$ at a flow rate of $300 \mu \mathrm{L} / \mathrm{min}$ and remained isocratic for $5 \mathrm{~min}$ before linearly decreasing in $1 \mathrm{~min}$ to $10 \% \mathrm{~B}$. The column was then re-equilibrated with $10 \% \mathrm{~B}$ for 9 min before the next injection. The total analysis time for each sample was $45 \mathrm{~min}$. The injection volume was $10 \mu \mathrm{L}$ and the tray temperature was maintained at $12{ }^{\circ} \mathrm{C}$. High resolution mass spectrometry was carried out in both positive and negative ESI ionization modes with a spray voltage of $4.5 \mathrm{kV}$ and capillary temperature of $320^{\circ} \mathrm{C}$. The mass range was acquired from $m / z, 150$ to 1500 .

Multi-fragmentation $\left(\mathrm{MS}^{\mathrm{n}}\right)$ experiments were accomplished for the negative ionization mode on an Orbitrap analyser, CID (The collision-induced dissociation) was utilized with a normalized collision energy of 35\%, activation Q of $0.250 \mathrm{~ms}$, and activation time of $30.000 \mathrm{~ms}$ applied on ions of most intense, 2nd most intense, and 3rd most intense peaks for $\mathrm{MS}^{2}, \mathrm{MS}^{3}$, and $\mathrm{MS}^{4}$, respectively at an isolation width of 3 microns with 5 microscans. Resolution was at $15,000 \mathrm{~m} / \Delta \mathrm{m}_{50 \%}$, while the minimum ion signal threshold was set to 500. Fragment mass tolerance for molecular formula detection was set to $\pm 5 \mathrm{ppm}$.

Raw data were initially sliced into two data sets based on the ionization mode, using the MassConvert tool from ProteoWizard [50]. The sliced data sets were imported into MZmine2.10 [51]; a framework for differential analysis of mass spectrometry data. The high-resolution mass spectral $\left(\mathrm{MS}^{1}\right)$ data set was deconvoluted and deisotoped, while mass adducts, fragments, as well as complexes were primarily identified and sorted with MZmine 2.10. The spectra were crop-filtered from 2 to $35 \mathrm{~min}$. The peaks in the samples and blanks were detected using the chromatogram builder. Mass ion 
peaks were isolated with a centroid detector threshold that was greater than the noise level set to 1.0E4 and an MS level of 1. Following this, the chromatogram builder was used with a minimum time span set to $0.2 \mathrm{~min}$, and the minimum height and $\mathrm{m} / \mathrm{z}$ tolerance to $1.0 \mathrm{E} 4$ and $0.001 \mathrm{~m} / \mathrm{z}$ or $5.0 \mathrm{ppm}$, respectively. Chromatogram deconvolution was then performed to detect the individual peaks. The local minimum search algorithm (chromatographic threshold: 90\%, search minimum in RT range: 0.4 min, minimum relative height: $5 \%$, minimum absolute height: $3.0 \mathrm{E} 4$, minimum ratio of peak top/edge: 2 , and peak duration range: $0.3-5 \mathrm{~min}$ ) was applied. Isotopes were also identified using the isotopic peaks grouper $(\mathrm{m} / \mathrm{z}$ tolerance: $0.001 \mathrm{~m} / \mathrm{z}$ or $5.0 \mathrm{ppm}$, retention time tolerance: 0.2 absolute (min), maximum charge: 2, and representative isotope: most intense). The retention time normalizer $(\mathrm{m} / \mathrm{z}$ tolerance: $0.001 \mathrm{~m} / \mathrm{z}$ or $5.0 \mathrm{ppm}$, retention time tolerance: 5.0 absolute $(\mathrm{min})$, and minimum standard intensity: 5.0E3) was used to reduce inter-batch variation. The peak lists were all aligned using the join aligner parameters set to $\mathrm{m} / \mathrm{z}$ tolerance: $0.001 \mathrm{~m} / \mathrm{z}$ or $5.0 \mathrm{ppm}$, weight for $\mathrm{m} / \mathrm{z}: 20$, retention time tolerance: 5.0 relative (\%), weight for RT: 20. Missing peaks were detected using the gap filling peak finder (intensity tolerance: $1.0 \%, \mathrm{~m} / \mathrm{z}$ tolerance: $0.001 \mathrm{~m} / \mathrm{z}$ or $5.0 \mathrm{ppm}$, and retention time tolerance of 0.5 absolute $(\mathrm{min})$ ). An adduct search was performed for $\mathrm{Na}-\mathrm{H}, \mathrm{K}-\mathrm{H}, \mathrm{NH}_{4}$, formate, and $\mathrm{ACN}+\mathrm{H}$ (RT tolerance: 0.2 absolute $(\mathrm{min}), \mathrm{m} / \mathrm{z}$ tolerance: $0.001 \mathrm{~m} / \mathrm{z}$ or $5.0 \mathrm{ppm}$, max relative adduct peak height: 30\%). Additionally, a complex search was performed (ionization method: $[\mathrm{M}+\mathrm{H}]^{+}$for ESI positive mode and $[\mathrm{M}-\mathrm{H}]^{-}$for ESI negative mode, retention time tolerance: 0.2 absolute $(\mathrm{min}), \mathrm{m} / \mathrm{z}$ tolerance: $0.001 \mathrm{~m} / \mathrm{z}$ or $5.0 \mathrm{ppm}$, and with maximum complex peak height of $50 \%$ ). The processed data set was then subjected to molecular formula prediction and peak identification. An accustomed library was created by employing an algorithm to use the molecular formula data set from Antibase ${ }^{\circledR}$ (February 2012) and Marinlit ${ }^{\circledR}$ (September 2012) from which the monoisotopic exact masses were recalculated. The accustomed library was used instead of the manually curated Antibase and MarinLit databases, which do not differentiate between monoisotopic, average, and most abundant mass. The created library was then coupled to MZmine and employed as the custom database for peak identification and dereplication. "Hits" and unidentified peaks (Supplementary Tables S2, and Tables 1 and 2) were double checked against the MS raw data in Xcalibur 2.1.

For NMR analysis, sample extracts as well as media blanks were prepared at a concentration of $5 \mathrm{mg}$ in $600 \mu \mathrm{L} \mathrm{DMSO}-d_{6}$. For the presaturation experiments, the water peak was suppressed and 16 scans were recorded on a $400 \mathrm{MHz}$ NMR system (JEOL, Tokyo, Japan), equipped with the 40TH5AT/FG probe.

Presaturation NMR spectra were processed using MestReNova (Mnova 8.1.0) software (Mestrelab Research, Santiago de Compostela, Spain). The spectral data of samples were stacked, superimposed, and normalized to a constant sum of 100 , and each data point was set to be a fraction of the total integral [52]. Baseline correction was accomplished with Whittaker Smoother, apodized with Gaussian 1.0, and smoothing done with Savitzy-Golay. The spectra were then binned, using a spectral width of $0.04 \mathrm{ppm}$. The NMR and MS spectral data were converted to an ASCII text file and imported into Excel. The data was sorted and organized to remove background peaks that belonged to the culture media. For the NMR data, the solvent peak columns were also deleted. The sorted data was then exported to SIMCA 13.0.2 (Umetrics, Umeå, Sweden) to determine the significant production of unique 
secondary metabolites between culture variables. Pareto scaling was used for both NMR and MS spectral data sets. PCA, HCA and supervised OPLS-DA were used to evaluate the best culture method.

\subsection{Purification of Actinosporins $A$ and $B$}

Actinokineospora strain EG49 was fermented in 162 L-Erlenmeyer flasks, each containing $1 \mathrm{~L}$ of ISP2 medium at $30{ }^{\circ} \mathrm{C}$ for 7 days under shaking at $150 \mathrm{rpm}$. After 7 days of growth, the culture broth was filtered and extracted with $10 \mathrm{~L}$ ethyl acetate. The ethyl acetate extract was concentrated under reduced pressure and chromatographed on a silica gel column, and eluted with increasing ratios of $\mathrm{MeOH}$ in $\mathrm{CHCl}_{3}$ from $10 \%$ to $100 \%$. The fraction $(745 \mathrm{mg}$ ) collected with $40 \% \mathrm{MeOH}$ was further fractionated by gel filtration on Sephadex LH-20 with increasing ratio of $\mathrm{MeOH}$ to yield fraction 2 $(83 \mathrm{mg}$ ) eluted at $60 \% \mathrm{MeOH}$ in water. Finally, fraction 1 was purified on a semi-preparative HPLC system from Agilent (QuatPump G1311A, Degasser G1322A, Controller ALS G1313A, UV detector G1315A and Fraction collector G1364C). Acetonitrile (MeCN) and water buffered with $0.05 \%$ trifluoroacetic acid were used as solvents. Gradient elution with $10 \%$ to $100 \% \mathrm{MeCN}$ in 20 min at a flow rate of $4 \mathrm{~mL} / \mathrm{min}$ yielded the pure compounds $\mathbf{1}$ and 2 at a retention time of 7.3 and $9.3 \mathrm{~min}$, respectively.

\subsection{Compound Characterisation}

UV spectra were recorded on a Jasco V650 UV/vis spectrophotometer (Essex, UK), IR spectra were recorded on a Bruker Tensor 27 FT-IR spectrometer (Bremen, Germany). NMR spectra were recorded at $30{ }^{\circ} \mathrm{C}$ a Varian $600 \mathrm{MHz}$ Unity INOVA spectrometer (Palo Alto, CA, USA) equipped with a triple resonance cold probe. The ${ }^{1} \mathrm{H}$ and ${ }^{13} \mathrm{C}$ NMR chemical shifts were referenced to the solvent peaks for $\mathrm{CD}_{3} \mathrm{OD}-d_{4}$ at $\delta_{\mathrm{H}} 3.30$ and $\delta_{\mathrm{C}} 49.0$, respectively. ${ }^{13} \mathrm{C}$ NMR spectra were acquired using the Standard Varian s2pul Pulse Sequence. Spectrometer frequency was $150.81 \mathrm{MHz}$, number of scans used was 5000, receiver gain at 30, relaxation delay set at 0.01 s. Spectral width at $37878.8 \mathrm{~Hz}$. For HMBC experiments, pulse sequence gHMBCAD was used, number of scans was 16, receiver gain at 30, relaxation delay used was $0.8 \mathrm{~s}$, spectral width was $9615.4 \mathrm{~Hz}$ for F2 and $33181.3 \mathrm{~Hz}$ for F1 with an acquired size of 2048 and $256 \mathrm{k}$, respectively. The average value for the 2 to 3 bond coupling constant was optimized to $8 \mathrm{~Hz}$. For the HSQC-EDITED experiment, the pulse sequence gHSQC was used. Number of scans was 4 , receiver gain at 30, relaxation delay at 1.0000 . The average value of the one bond coupling constant was optimized at $140 \mathrm{~Hz}$.

The ROESYAD experiment was utilized to determine the stereochemistry of actinosporin A. However, NOESY experiments were performed for small molecules, at $600 \mathrm{MHz}$, and exhibited zero or very small NOEs at a range of mixing times. The ROESYAD experiment, on the other hand, did not show any TOCSY artifacts for the correlations in question. The mixing time used for the ROESY experiment was $400 \mathrm{~ms}$.

Actinosporin A (1): $3.8 \mathrm{mg}$ of an orange amorphous powder; $[\alpha]_{D}^{25}+180$ (c $\left.0.002, \mathrm{MeOH}\right)$; UV (MeOH): $\lambda_{\max }(\log \varepsilon)=227$ (4.41), 312 (4.06), 408 (3.61) nm; IR: 3389, 3206, 1677, 1644, 1625, $1364 \mathrm{~cm}^{-1} ;{ }^{1} \mathrm{H}\left(\mathrm{CD}_{3} \mathrm{OD}, 600 \mathrm{MHz}\right)$, and ${ }^{13} \mathrm{C} \mathrm{NMR}\left(\mathrm{CD}_{3} \mathrm{OD}, 125 \mathrm{MHz}\right)$ data see Table 3; HR-ESIMS: found at $m / z 613.1915[\mathrm{M}+\mathrm{H}]^{+}$, calcd for $\mathrm{C}_{31} \mathrm{H}_{33} \mathrm{O}_{13},(613.1916)$, and at $m / z 611.1768[\mathrm{M}-\mathrm{H}]^{-}$, calcd for $\mathrm{C}_{31} \mathrm{H}_{31} \mathrm{O}_{13}(611.1770)$. 
Actinosporin B (2): $0.8 \mathrm{mg}$ of an orange amorphous powder; $[\alpha]_{D}^{25}+18.0$ (c $\left.0.05, \mathrm{MeOH}\right)$; UV $(\mathrm{MeOH}): \lambda_{\max }(\log \varepsilon)=254(4.41), 379(4.06), 408(3.61) \mathrm{nm} ;{ }^{1} \mathrm{H} \mathrm{NMR}\left(\mathrm{CD}_{3} \mathrm{OD}, 600 \mathrm{MHz}\right) \delta_{\mathrm{H}} 7.96$ $\left(1 \mathrm{H}, \mathrm{d}, J_{11,10} 7.4, \mathrm{H}-11\right), 7.87\left(1 \mathrm{H}, \mathrm{dd}, J_{10,11} 7.4, J_{10,9} 8.2, \mathrm{H}-10\right), 7.79\left(1 \mathrm{H}, \mathrm{d}, J_{5,6} 7.8, \mathrm{H}-5\right), 7.70(1 \mathrm{H}$, d, $\left.J_{9,10} 8.2, \mathrm{H}-9\right), 7.62\left(1 \mathrm{H}, \mathrm{d}, J_{6,5} 7.8, \mathrm{H}-6\right), 5.64(1 \mathrm{H}$, br s, H-1'), $4.93(1 \mathrm{H}, \mathrm{bs}, \mathrm{H}-1), 4.83(1 \mathrm{H}, \mathrm{d}$, $\left.J_{3 \mathrm{~A}, 3 \mathrm{~B}} 11.6, \mathrm{H}-13 \mathrm{~A}\right), 4.01$ (2H, m, H-2 and $\left.\mathrm{H}-2^{\prime}\right), 3.51\left(1 \mathrm{H}, \mathrm{m}, \mathrm{H}-5^{\prime}\right)$ 3.33-3.53 (underneath HOD peak, H-13B, H-3', H-4'), 3.01 (1H, d, $\left.J_{4 \mathrm{~A}, 4 \mathrm{~B}} 13.2, \mathrm{H}-4 \mathrm{~A}\right), 2.90$ (d, $\left.J_{4 \mathrm{~B}, 4 \mathrm{~A}} 13.2, \mathrm{H}-4 \mathrm{~B}\right), 1.10$ (3H, d, $J_{6^{\prime}, 5^{\prime}} 6.3$, H-6'); ${ }^{13} \mathrm{C}$ NMR (151 MHz, DMSO) $\delta=181.0$ (C-7), 156.9 (C-8), 140.7 (C-4a), 135.6 (C-11a), 133.27 (C-6a), 133.31 (C-12a), 123.9 (C-7a), 122.0 (C-11), 116.0 (C-12b), 72.5 (C-13), 71.7 (C-3), 71.5 (C-4'), $71.4\left(\mathrm{C}-3^{\prime}\right), 70.5$ (C-2'), 70.4 (C-2), 64.0 (C-5'), and 42.7 (C-4); HR-ESIMS: [M - H] found at $\mathrm{m} / \mathrm{z}$ 501.1402, calcd for $\mathrm{C}_{25} \mathrm{H}_{25} \mathrm{O}_{11}(501.1402) ;[\mathrm{M}+\mathrm{H}]^{+}$found at $\mathrm{m} / \mathrm{z}$ 503.1554, calcd for $\mathrm{C}_{25} \mathrm{H}_{27} \mathrm{O}_{11}$ (503.1548).

\subsection{Antitrypanosomal Activity Testing}

Antitrypanosomal activity was tested following the protocol of Huber and Koella [53]. Briefly, $10^{4}$ trypanosomes per $\mathrm{mL}$ of the Trypanosoma brucei brucei strain TC 221 were cultivated in Complete Baltz Medium. Trypanosomes were tested in 96-well plate chambers against different concentrations of test substances at $0.25-40 \mu \mathrm{M}$ in $1 \%$ DMSO to a final volume of $200 \mu \mathrm{L}$. For controls, $1 \%$ DMSO as well as parasites without any test compound were used simultanously in each plate to show that DMSO did not perturb the results. The plates were then incubated at $37{ }^{\circ} \mathrm{C}$ in an atmosphere of $5 \% \mathrm{CO}_{2}$ for $24 \mathrm{~h}$. After addition of $20 \mu \mathrm{L}$ of Alamar Blue, the activity was measured after 48 and $72 \mathrm{~h}$ by light absorption using an MR 700 Microplate Reader (Dynatech Engineering Ltd., Willenhall, UK) at a wavelength of $550 \mathrm{~nm}$ with a reference wavelength of $650 \mathrm{~nm}$ The $I C_{50}$ values of the test compound were quantified by linear interpolation of three independent measurements.

\subsection{Cytotoxicity Assay}

Macrophages (J774.1) were cultured in complete medium without phenol red in the absence or presence of increasing concentrations of the test compounds $(0.25-200 \mu \mathrm{M})$ at a cell density of $1 \times 10^{5}$ cells $/ \mathrm{mL}$ for $24 \mathrm{~h}, 37{ }^{\circ} \mathrm{C}, 5 \% \mathrm{CO}_{2}$, and $95 \%$ humidity. Following the addition of $20 \mu \mathrm{L}$ of Alamar Blue, the plates were incubated and the optical densities were determined after 48 and $72 \mathrm{~h}$ in the same manner as described for the anti-trypansomal assay, using a test wavelength of $540 \mathrm{~nm}$ and a reference wavelength of $630 \mathrm{~nm}$.

\section{Conclusions}

Metabolomic profiling of Actinokineospora sp. EG49 crude extracts utilizing both high resolution mass spectrometry and nuclear magnetic resonance was employed to optimize culture conditions and extraction procedures. We conclude that ISP2 broth culture is more prolific and offers higher chemical diversity than the other three approaches employed in this study. With respect to the isolation of quinone analogues, ethyl acetate extraction of culture supernatants was superior to methanolic extraction of cell pellets. NMR and mass spectral data were successfully used as complementary tools to provide information about the known and the putative new compounds from EG49. Furthermore, actinosporins A 
and B, new $O$-glycosylated angucyclines, were isolated from the sponge-derived Actinokineospora strain EG49. Actinosporin A exhibited activity against $T$. brucei bruce $i$ with an $I C_{50}$ value of $15 \mu \mathrm{M}$. This is the first report on the isolation of angucycline derivatives from the genus Actinokineospora.

\section{Acknowledgments}

We thank H. Bruhn, A. Stich, H. Moll (University of Würzburg), and G. Pradel (University of Aachen) for performing the anti-parasitic screening assays. We also thank C. Dowells (Strathclyde Institute of Pharmacy and Biomedical Sciences) for performing the MS and NMR measurements for the dereplication study.

This work was supported by the Deutsche Forschungsgemeinschaft awarded (SFB 630-TPA5: Recognition, preparation, and functional analysis of agents against infectious diseases) to UH and the Royal Society Seed Grant (115773: Marine symbionts and terrestrial endophytes for industrial biotechnology of novel antibiotics) awarded to REE.

\section{Conflicts of Interest}

The authors declare no conflict of interest.

\section{References}

1. Yuliana, N.D.; Khatib, A.; Choi, Y.H.; Verpoorte, R. Metabolomics for bioactivity assessment of natural products. Phytother. Res. 2011, 25, 157-169.

2. Tawfike, A.; Viegelmann, C.; Edrada-Ebel, R. Metabolomics and Dereplication Strategies in Natural Products. In Metabolomics Tools for Natural Product Discovery: Methods and Protocols: Methods in Molecular Biology; Roessner, U., Dias, D.A., Eds.; Humana Press: New York, NY, USA, 2013; pp. 227-244.

3. Kjer, J.; Debbab, A.; Aly, A.H.; Proksch, P. Methods for isolation of marine-derived endophytic fungi and their bioactive secondary products. Nat. Protoc. 2010, 5, 479-490.

4. Blunt, J.W.; Copp, B.R.; Keyzers, R.A.; Munro, M.H.; Prinsep, M.R. Marine natural products. Nat. Prod. Rep. 2013, 30, 237-323.

5. Shin, M.H.; Lee do, Y.; Liu, K.H.; Fiehn, O.; Kim, K.H. Evaluation of sampling and extraction methodologies for the global metabolic profiling of Saccharophagus degradans. Anal. Chem. 2010, 82, 6660-6666.

6. Bosque-Sendra, J.M.; Cuadros-Rodriguez, L.; Ruiz-Samblas, C.; de la Mata, A.P. Combining chromatography and chemometrics for the characterization and authentication of fats and oils from triacylglycerol compositional data-A review. Anal. Chim. Acta 2012, 724, 1-11.

7. Ali, K.; Iqbal, M.; Korthout, H.A.; Maltese, F.; Fortes, A.M.; Pais, M.S.; Verpoorte, R.; Choi, Y.H. NMR spectroscopy and chemometrics as a tool for anti-TNFalpha activity screening in crude extracts of grapes and other berries. Metabolomics 2012, 8, 1148-1161.

8. Zheng, L.; Watson, D.G.; Johnston, B.F.; Clark, R.L.; Edrada-Ebel, R.; Elseheri, W. A chemometric study of chromatograms of tea extracts by correlation optimization warping in conjunction with PCA, support vector machines and random forest data modeling. Anal. Chim. Acta 2009, 642, 257-265. 
9. Mitova, M.I.; Murphy, A.C.; Lang, G.; Blunt, J.W.; Cole, A.L.; Ellis, G.; Munro, M.H. Evolving trends in the dereplication of natural product extracts. 2. The isolation of chrysaibol, an antibiotic peptaibol from a New Zealand sample of the mycoparasitic fungus Sepedonium chrysospermum. J. Nat. Prod. 2008, 71, 1600-1603.

10. Lang, G.; Mayhudin, N.A.; Mitova, M.I.; Sun, L.; van der Sar, S.; Blunt, J.W.; Cole, A.L.; Ellis, G.; Laatsch, H.; Munro, M.H. Evolving trends in the dereplication of natural product extracts: New methodology for rapid, small-scale investigation of natural product extracts. J. Nat. Prod. 2008, 71, 1595-1599.

11. Krug, D.; Zurek, G.; Schneider, B.; Garcia, R.; Muller, R. Efficient mining of myxobacterial metabolite profiles enabled by liquid chromatography-electrospray ionisation-time-of-flight mass spectrometry and compound-based principal component analysis. Anal. Chim. Acta 2008, 624, 97-106.

12. Mansson, M.; Phipps, R.K.; Gram, L.; Munro, M.H.; Larsen, T.O.; Nielsen, K.F. Explorative solid-phase extraction (E-SPE) for accelerated microbial natural product discovery, dereplication, and purification. J. Nat. Prod. 2010, 73, 1126-1132.

13. Hou, Y.; Braun, D.R.; Michel, C.R.; Klassen, J.L.; Adnani, N.; Wyche, T.P.; Bugni, T.S. Microbial strain prioritization using metabolomics tools for the discovery of natural products. Anal. Chem. 2012, 84, 4277-4283.

14. Ebada, S.S.; Edrada, R.A.; Lin, W.; Proksch, P. Methods for isolation, purification and structural elucidation of bioactive secondary metabolites from marine invertebrates. Nat. Protoc. 2008, 3, 1820-1831.

15. Lampert, Y.; Kelman, D.; Nitzan, Y.; Dubinsky, Z.; Behar, A.; Hill, R.T. Phylogenetic diversity of bacteria associated with the mucus of Red Sea corals. FEMS Microbiol. Ecol. 2008, 64, 187-198.

16. Prieto-Davo, A.; Villarreal-Gomez, L.J.; Forschner-Dancause, S.; Bull, A.T.; Stach, J.E.; Smith, D.C.; Rowley, D.C.; Jensen, P.R. Targeted search for actinomycetes from near-shore and deep-sea marine sediments. FEMS Microbiol. Ecol. 2013, 84, 510-518.

17. Bull, A.T.; Stach, J.E. Marine actinobacteria: New opportunities for natural product search and discovery. Trends Microbiol. 2007, 15, 491-499.

18. Vicente, J.; Stewart, A.; Song, B.; Hill, R.; Wright, J. Biodiversity of actinomycetes associated with Caribbean sponges and their potential for natural product discovery. Mar. Biotechnol. 2013, $15,413-424$.

19. Zhang, H.; Zhang, W.; Jin, Y.; Jin, M.; Yu, X. A comparative study on the phylogenetic diversity of culturable actinobacteria isolated from five marine sponge species. Antonie Van Leeuwenhoek 2008, 93, 241-248.

20. Subramani, R.; Aalbersberg, W. Marine actinomycetes: An ongoing source of novel bioactive metabolites. Microbiol. Res. 2012, 167, 571-580.

21. Jiao, R.H.; Xu, H.; Cui, J.T.; Ge, H.M.; Tan, R.X. Neuraminidase inhibitors from marine-derived actinomycete Streptomyces seoulensis. J. Appl. Microbiol. 2013, 114, 1046-1053.

22. Engelhardt, K.; Degnes, K.F.; Kemmler, M. Production of a new thiopeptide antibiotic, TP-1161, by a marine-derived Nocardiopsis species. Appl. Environ. Microbiol. 2010, doi:10.1128/AEM.00741-10. 
23. Pimentel-Elardo, S.M.; Kozytska, S.; Bugni, T.S.; Ireland, C.M.; Moll, H.; Hentschel, U. Anti-parasitic compounds from Streptomyces sp. strains isolated from Mediterranean sponges. Mar. Drugs 2010, 8, 373-380.

24. Olano, C.; Mendez, C.; Salas, J.A. Antitumor compounds from marine actinomycetes. Mar. Drugs 2009, 7, 210-248.

25. Abdelmohsen, U.R.; Szesny, M.; Othman, E.M.; Schirmeister, T.; Grond, S.; Stopper, H.; Hentschel, U. Antioxidant and anti-protease activities of diazepinomicin from the sponge-associated Micromonospora strain RV115. Mar. Drugs 2012, 10, 2208-2221.

26. Tabares, P.; Pimentel-Elardo, S.M.; Schirmeister, T.; Hunig, T.; Hentschel, U. Anti-protease and immunomodulatory activities of bacteria associated with Caribbean sponges. Mar. Biotechnol. 2011, $13,883-892$.

27. Schneemann, I.; Kajahn, I.; Ohlendorf, B.; Zinecker, H.; Erhard, A.; Nagel, K.; Wiese, J.; Imhoff, J.F. Mayamycin, a cytotoxic polyketide from a Streptomyces strain isolated from the marine sponge Halichondria panicea. J. Nat. Prod. 2010, 73, 1309-1312.

28. Asolkar, R.N.; Kirkland, T.N.; Jensen, P.R.; Fenical, W. Arenimycin, an antibiotic effective against rifampin- and methicillin-resistant Staphylococcus aureus from the marine actinomycete Salinispora arenicola. J. Antibiot. 2010, 63, 37-39.

29. Abdelmohsen, U.R.; Zhang, G.L.; Philippe, A.; Schmitz, W.; Pimentel-Elardo, S.M.; Hertlein-Amslinger, B.; Hentschel, U.; Bringmann, G. Cyclodysidins A-D, cyclic lipopeptides from the marine sponge-derived Streptomyces strain RV15. Tetrahedron Lett. 2012, 53, 23-29.

30. Tang, X.; Zhou, Y.; Zhang, J.; Ming, H.; Nie, G.X.; Yang, L.L.; Tang, S.K.; Li, W.J. Actinokineospora soli sp. nov., a thermotolerant actinomycete isolated from soil, and emended description of the genus Actinokineospora. Int. J. Syst. Evol. Microbiol. 2012, 62, 1845-1849.

31. Lisdiyanti, P.; Otoguro, M.; Ratnakomala, S.; Lestari, Y.; Hastuti, R.D.; Triana, E.; Katsuhiko, A.; Widyastuti, Y. Actinokineospora baliensis sp. nov., Actinokineospora cibodasensis sp. nov. and Actinokineospora cianjurensis sp. nov., isolated from soil and plant litter. Int. J. Syst. Evol. Microbiol. 2010, 60, 2331-2335.

32. Abdelmohsen, U.R.; Pimentel-Elardo, S.M.; Hanora, A.; Radwan, M.; Abou-El-Ela, S.H.; Ahmed, S.; Hentschel, U. Isolation, phylogenetic analysis and anti-infective activity screening of marine sponge-associated actinomycetes. Mar. Drugs 2010, 8, 399-412.

33. Kharel, M.K.; Pahari, P.; Shepherd, M.D.; Tibrewal, N.; Nybo, S.E.; Shaaban, K.A.; Rohr, J. Angucyclines: Biosynthesis, mode-of-action, new natural products, and synthesis. Nat. Prod. Rep. 2012, 29, 264-325.

34. Rohr, J.; Thiericke, R. Angucycline group antibiotics. Nat. Prod. Rep. 1992, 9, 103-137.

35. Kharel, M.K.; Pahari, P.; Lian, H.; Rohr, J. Enzymatic total synthesis of rabelomycin, an angucycline group antibiotic. Org. Lett. 2010, 12, 2814-2817.

36. Shaaban, K.A.; Srinivasan, S.; Kumar, R.; Damodaran, C.; Rohr, J.; Landomycins, P.-W. Cytotoxic angucyclines from Streptomyces cyanogenus S-136. J. Nat. Prod. 2011, 74, 2-11.

37. Korynevska, A.; Heffeter, P.; Matselyukh, B.; Elbling, L.; Micksche, M.; Stoika, R.; Berger, W. Mechanisms underlying the anticancer activities of the angucycline landomycin E. Biochem. Pharmacol. 2007, 74, 1713-1726. 
38. Shaaban, K.A.; Stamatkin, C.; Damodaran, C.; Rohr, J. 11-Deoxylandomycinone and landomycins X-Z, new cytotoxic angucyclin(on)es from a Streptomyces cyanogenus K62 mutant strain. J. Antibiot. 2011, 64, 141-150.

39. Sasaki, E.; Ogasawara, Y.; Liu, H.W. A biosynthetic pathway for BE-7585A, a 2-thiosugar-containing angucycline-type natural product. J. Am. Chem. Soc. 2010, 132, 7405-7417.

40. Fotso, S.; Mahmud, T.; Zabriskie, T.M.; Santosa, D.A.; Sulastri, D.A.; Proteau, P.J. Angucyclinones from an Indonesian Streptomyces sp. J. Nat. Prod. 2008, 71, 61-65.

41. Guo, Z.K.; Liu, S.B.; Jiao, R.H.; Wang, T.; Tan, R.X.; Ge, H.M. Angucyclines from an insect-derived actinobacterium Amycolatopsis sp. HCa1 and their cytotoxic activity. Bioorg. Med. Chem. Lett. 2012, 22, 7490-7493.

42. Huang, H.; Yang, T.; Ren, X.; Liu, J.; Song, Y.; Sun, A.; Ma, J.; Wang, B.; Zhang, Y.; Huang, C.; et al. Cytotoxic angucycline class glycosides from the deep sea actinomycete Streptomyces lusitanus SCSIO LR32. J. Nat. Prod. 2012, 75, 202-208.

43. Bode, H.B.; Bethe, B.; Höfs, R.; Zeeck, A. Big effects from small changes: Possible ways to explore nature's chemical diversity. Chem. Biol. Chem. 2002, 3, 619-627.

44. Pluskal, T.; Castillo, S.; Villar-Briones, A.; Oresic, M. MZmine 2: Modular framework for processing, visualizing, and analyzing mass spectrometry-based molecular profile data. BMC Bioinf. 2010, 11, 395-397.

45. Pluskal, T.; Uehara, T.; Yanagida, M. Highly accurate chemical formula prediction tool utilizing high-resolution mass spectra, MS/MS fragmentation, heuristic rules, and isotope pattern matching. Anal. Chem. 2012, 84, 4396-4403.

46. Hoet, S.; Opperdoes, F.; Brun, R.; Quetin-Leclercq, J. Natural products active against African trypanosomes: A step towards new drugs. Nat. Prod. Rep. 2004, 21, 353-364.

47. Tang, H.; Mechref, Y.; Novotny, M.V. Automated interpretation of MS/MS spectra of oligosaccharides. Bioinformatics 2005, 21, 431-439.

48. Vanhamme, L.; Paturiaux-Hanocq, F.; Poelvoorde, P.; Nolan, D.P.; Lins, L.; van Den Abbeele, J.; Pays, A.; Tebabi, P.; van Xong, H.; Jacquet, A.; et al. Apolipoprotein L-I is the trypanosome lytic factor of human serum. Nature 2003, 422, 83-87.

49. Jacobs, R.T.; Nare, B.; Phillips, M.A. State of the art in African trypanosome drug discovery. Curr. Top. Med. Chem. 2011, 11, 1255-1274.

50. ProteoWizard Software Foundation. ProteoWizard Homepage. Available online: http://proteowizard.sourceforge.net/ (accessed on 22 April 2012).

51. Sourceforge Project Website. Available online: http://sourceforge.net/projects/mzmine/ (accessed on 22 April 2012).

52. Craig, A.; Cloarec, O.; Holmes, E.; Nicholson, J.K.; Lindon, J.C. Scaling and normalization effects in NMR spectroscopic metabonomic data sets. Anal. Chem. 2006, 78, 2262-2267.

53. Huber, W.; Koella, J.C. A comparison of three methods of estimating $\mathrm{EC}_{50}$ in studies of drug resistance of malaria parasites. Acta Trop. 1993, 55, 257-261.

(C) 2014 by the authors; licensee MDPI, Basel, Switzerland. This article is an open access article distributed under the terms and conditions of the Creative Commons Attribution license (http://creativecommons.org/licenses/by/3.0/). 